\title{
Dendritic and Axonal L-Type Calcium Channels Cooperate to Enhance Motoneuron Firing Output during Drosophila Larval Locomotion
}

\author{
Dimitrios Kadas, Aylin Klein, Niklas Krick, Jason W. Worrell, Stefanie Ryglewski, and Carsten Duch \\ Johannes Gutenberg University of Mainz, Institute of Developmental Biology and Neurobiology, 55099 Mainz, Germany
}

Behaviorally adequate neuronal firing patterns are critically dependent on the specific types of ion channel expressed and on their subcellular localization. This study combines in situ electrophysiology with genetic and pharmacological intervention in larval Drosophila melanogaster of both sexes to address localization and function of L-type like calcium channels in motoneurons. We demonstrate that Dmca1D ( $\mathrm{Ca}_{\mathrm{v}} 1$ homolog) L-type like calcium channels localize to both the somatodendritic and the axonal compartment of larval crawling motoneurons. In situ patch-clamp recordings in genetic mosaics reveal that Dmca1D channels increase burst duration and maximum intraburst firing frequencies during crawling-like motor patterns in semi-intact animals. Genetic and acute pharmacological manipulations suggest that prolonged burst durations are caused by dendritically localized Dmca1D channels, which activate upon cholinergic synaptic input and amplify EPSPs, thus indicating a conserved function of dendritic L-type channels from Drosophila to vertebrates. By contrast, maximum intraburst firing rates require axonal calcium influx through Dmca1D channels, likely to enhance sodium channel de-inactivation via a fast afterhyperpolarization through BK channel activation. Therefore, in unmyelinated Drosophila motoneurons different functions of axonal and dendritic L-type like calcium channels likely operate synergistically to maximize firing output during locomotion.

Key words: calcium channel; Drosophila; L-type channel; locomotion; motoneuron

\section{Significance Statement}

Nervous system function depends on the specific excitabilities of different types of neurons. Excitability is largely shaped by different combinations of voltage-dependent ion channels. Despite a high degree of conservation, the huge diversity of ion channel types and their differential localization pose challenges in assigning distinct functions to specific channels across species. We find a conserved role, from fruit flies to mammals, for L-type calcium channels in augmenting motoneuron excitability. As in spinal cord, dendritic L-type channels amplify excitatory synaptic input. In contrast to spinal motoneurons, axonal L-type channels enhance firing rates in unmyelinated Drosophila motoraxons. Therefore, enhancing motoneuron excitability by L-type channels seems an old strategy, but localization and interactions with other channels are tuned to species-specific requirements.

\section{Introduction}

Motoneurons (MNs) are the relay output from the central pattern generating ( $\mathrm{CPG}$ ) networks to the muscles. Although CPGs generate the principle patterns of spiking output to the muscles (Kiehn and Kullander, 2004; Grillner et al., 2005; Marder et al., 2005), the final motor output depends not only on network connec-

Received April 20, 2017; revised Sept. 18, 2017; accepted Sept. 26, 2017.

Author contributions: D.K. and S.R. designed research; D.K., A.K., N.K., J.W.W., S.R., and C.D. performed research; D.K., A.K., N.K., J.W.W., S.R., and C.D. analyzed data; S.R. and C.D. wrote the paper.

This work was supported by the German Research Foundation to C.D. (Du-331/6-1) and S.R. (Ry 117/3-1). We thank Dr. R. B. Levine (University of Arizona, Tucson, Arizona) for helpful comments on the paper.

The authors declare no competing financial interests.

Correspondence should be addressed to Dr. Carsten Duch, Institute of Developmental Biology and Neurobiology, Johannes Gutenberg University of Mainz, Colonel-Kleinmann Weg 2, 55099 Mainz, Germany. E-mail: cduch@uni-mainz.de.

DOI:10.1523/JNEUROSCI.1064-17.2017

Copyright $\odot 2017$ the authors $\quad 0270-6474 / 17 / 3710971-12 \$ 15.00 / 0$ tivity but also on the intrinsic properties of MNs, because these compute synaptic input far beyond threshold summation (Kiehn, 1991; Kiehn et al., 2000; Heckman et al., 2003). Therefore, addressing the specific contributions of $\mathrm{MN}$ membrane currents to the production of rhythmic motor output is critical to understanding the control of movement in healthy and diseased animals.

L-type $\mathrm{Ca}^{2+}$ channels play important roles in regulating spinal MN excitability. Localized to dendrites, these channels may contribute to persistent inward current (PIC) and amplify synaptic input, especially in the presence of aminergic modulation (Heckman et al., 2003, 2005; Hultborn et al., 2013). The Drosophila homolog of vertebrate $\mathrm{Ca}_{\mathrm{v}} 1 \mathrm{~L}$-type $\mathrm{Ca}^{2+}$ channels is DmcalD (Zheng et al., 1995). Somatic patch-clamp recordings from larval Drosophila crawling MNs indicate a conserved somatodendritic localization of L-type channels (Worrell and Levine, 2008). However, the function of L-type channels in invertebrate neu- 
rons and the degree to which the regulation of MN excitability is conserved from insects to vertebrates remain incompletely understood.

This study shows directly by immunocytochemistry that Dmca1D localizes to patches of larval Drosophila MN dendritic membrane, but in contrast to spinal MNs, L-type channels also localize to the axons of Drosophila motoneurons. In situ patchclamp recordings in genetic mosaics reveal that L-type like channels increase burst duration and maximum intraburst firing frequencies during locomotion. Combining imaging and current-clamp recordings with acute pharmacological manipulation indicates that dendritic channels function to amplify excitatory synaptic drive, as in vertebrates. By contrast, axonal $\mathrm{Ca}^{2+}$ influx through L-type channels promotes maximum $\mathrm{MN}$ firing rates by enhancing $\mathrm{Na}^{+}$channel de-inactivation via a fast afterhyperpolarization that is caused by transient BK channel activation (Kadas et al., 2015).

\section{Materials and Methods}

Animals. Drosophila melanogaster were reared in standard plastic vials with foam stoppers on a yeast-cornmeal-syrup-agar diet at $25^{\circ} \mathrm{C}$ with a $12 \mathrm{~h}$ light/dark regimen. Wandering third instar larvae of both sexes were used for all experiments. Canton-S (CS; Bloomington Stock Center, 64349; RRID:BDSC_64349) and $\mathrm{w}^{1118}$ (Bloomington Stock Center, 3605; RRID: BDSC_3605) larvae were used as wild-type or wild-type-like controls. The homozygous viable allele of Dmca1D, AR66 (Eberl et al., 1998; obtained from Dr. D. Eberl, University of Iowa, Iowa City, IA), contains a point mutation causing a hypomorphic phenotype (Ren et al., 1998) and was used to assess the consequences of reduced Dmca1D function in all cells.

We used mosaic analysis with a repressible cell marker (MARCM; Lee, Luo, 2001) to create animals with few Dmca1D-null mutant MNs in an otherwise heterozygous background. We used the null mutant $X 10$ allele of Dmca1D (Bloomington Stock Center, 25141; RRID:BDSC_25141) to create a fly strain containing the $X 10$ allele behind a flippase target recognition site $(P$ nneoFRTry +$\} 40 A$;Bloomington Stock Center, 5759; RRID:BDSC_5759) to obtain $b^{1} C a-\alpha 1 D^{X 10} P$ \{neoFRTry+\}40A/CyO $P\{$ Act $G F P\} J M R 1$. This strain was crossed to a fly strain containing a heat shock inducible flippase and the GAL4 inhibitor GAL80 under the control of the strong tubulin promoter behind the respective flippase recognition target site $\left(P\{h s F L P\} 1, y^{1} w^{*} P\{U A S-m C D 8:: G F P . L\} P t p 4 E^{L L 4}\right.$; P\{tubPGAL80\}LL10 P\{neoFRT $\} 40 A ; P\{t u b P-G A L 4\} L L 7$; Bloomington Stock Center, 42725; RRID:BDSC_42725). The heat shock inducible flippase was activated by placing embryos $2 \mathrm{~h}$ after egg laying for $30 \mathrm{~min}$ from 25 to $34^{\circ} \mathrm{C}$. Egg laying was permitted on fresh grape juice agar for $1 \mathrm{~h}$.

To restrict Dmca1D-RNAi (VDRC, RRID:SCR_013805, stock 51491; and Bloomington Stock Center, 33413, HMS00294, RRID:BDSC_33413) knockdown to two identified MNs per ventral nerve cord hemisegment, expression was driven under the control of the even-skipped promoter (RN2-GAL4, Bloomington Stock Center, 7473; RRID:BDSC_7473; Fuijoka et al., 2003). RN2 expresses in MN1-Ib, which innervates muscle 1 with big type I terminal boutons and in MNISN-Is, which innervates multiple dorsal muscles via the intersegmental nerve (ISN) and has small type I terminals (Hoang, Chiba, 2001). MN1-Ib (or short MN1b) and MNISN-Is (or short MN1s) are also named by their embryonic identities as aCC and RP2, respectively (Fujioka et al., 2003). In all RNAi experiments inclusion of extra Dicer-2 (UAS-Drc2; Bloomington Stock Center, 24650; RRID:BDSC_24650; Dietzl et al., 2007) was used to increase knockdown strength as previously reported (Ryglewski et al., 2012; Hutchinson et al., 2014).

Because $R N 2$ is a relatively weak driver in the third instar, a flippase strategy was used to express the UAS-RNAi constructs in a mosaic fashion under the control of the particularly strong actin-GAL4 promoter. In this scheme, the flippase is driven by the weak $R N 2$ promoter to remove a stop cassette to activate the strong actin-GAL4 promoter. This resulted in strong RNAi expression in only a small subset of aCC and RPs neurons (Hartwig et al., 2008; fly strain courtesy of Dr. S. Sanyal, BIOGEN-Idec). This scheme creates genetic mosaics, so that non-GFP labeled MNs could be used as internal controls to evaluate RNAi knockdown efficacy. Although the VDRC stock 51491 has previously been reported to yield
$30-70 \%$ knockdown of Dmca1D current as recorded from larval MN somata (Worrell and Levine, 2008), we found that the TRiP RNAi construct (HMS00294, RRID:BDSC_33413) yielded a stronger and more reliable knockdown when tested by somatic patch-clamp recordings or by immunolabeling. Therefore, HMS00294 (full genotype: $y^{1} s c^{*} v^{1}$; $P\{$ TRiP.HMS00294\}attP2) was used to address the function of Dmca1D in larval MNs during locomotion. TRiP.HMS00294 has been targeted with a VALIUM vector (Vermillion-attB-loxP-Intron-UAS-MCS) to an attP-landing site on the third chromosome of Drosophila (Ni et al., 2009). As genetic controls, we used animals with the same VALIUM vector inserted at the same attP landing site in the same genetic background (Bloomington Stock Center, 35786; RRID:BDSC_35786), but without siRNAi (Ni et al., 2008).

Larval preparation. Third instar larvae were dissected in normal saline (composition in mM: $128 \mathrm{NaCl}, 2 \mathrm{KCl}, 1.8 \mathrm{CaCl}_{2}, 4 \mathrm{MgCl}_{2}, 5$ HEPES, and $\sim 35$ sucrose to adjust osmolality to $300 \mathrm{mOsm} / \mathrm{kg}^{-1} ; \mathrm{pH}$ was adjusted to 7.25 with $1 \mathrm{M} \mathrm{NaOH})$. Larvae were pinned dorsal side up in silicone elastomere (Sylgard 184, Dow Corning) lined Petri dishes with minute pins through the mouthhooks and the tail. Animals were dissected along the dorsal midline, and the dorsal cuticle and muscles were stretched laterally and pinned down with $2 \mathrm{~min}$ pins on each side. After removal of the gut and esophagus, the VNC was exposed, mounted onto an upright fixed stage Zeiss Axioskop 2 FS plus fluorescence microscope, and viewed with a $40 \times$ water-immersion objective. When constantly perfused with saline, $\sim 20 \%$ of the larval preparations spontaneously produced crawlinglike motor patterns as characterized by peristaltic waves of rhythmic contractions, which propagate from posterior to anterior (Fox et al., 2006; Heckscher et al., 2012).

Electrophysiology. Extracellular nerve root recordings were conducted as recently described (Kadas et al., 2015). To facilitate access to RP2 and aCC MNs with the recording electrode, the ganglionic sheath was digested by focally applying $1 \%$ protease (Protease type XIV from Streptomyces griseus; Sigma-Aldrich, catalog \#P5147; CAS 9036-06-0) in normal saline with a large patch pipette ( $1 \mathrm{M} \Omega$ tip resistance). Recording patch pipettes with a tip resistance of $6-8 \mathrm{M} \Omega$ were pulled from borosilicate glass $(1.5 \mathrm{~mm}$ outer diameter, $1.0 \mathrm{~mm}$ inner diameter, without filament, World Precision Instruments) with a vertical pipette puller (PC-10, Narishige). After protease treatment, the preparation was rinsed with $5 \mathrm{ml}$ of normal saline for 2 min before patching onto the MNs. For current-clamp recordings electrodes contained internal solution of the following composition (in $\mathrm{mm}$ ): 140 Kgluconate, $2 \mathrm{MgCl}_{2}, 2 \mathrm{Mg}$-ATP, 10 HEPES, 1.1 EGTA, glucose to adjust osmolality to $300 \mathrm{mOsm} / \mathrm{kg}^{-1}, \mathrm{pH} 7.25$. External solution was normal saline (see above). For voltage-clamp recordings of $\mathrm{Ca}^{2+}$ currents TEA-Cl (Sigma-Aldrich, catalog \#T2265, CAS 56-34-8) and 4-AP (Sigma-Aldrich, catalog \#275875; CAS 504-24-5) were used to block K ${ }^{+}$ currents, and TTX (300 nм; Roth Chemicals, catalog \#6973.1, CAS 436828-9) was used to block sodium current. The internal patch solution consisted of the following (in mM): $140 \mathrm{CsCl}, 2 \mathrm{Mg}$-ATP, $0.5 \mathrm{CaCl}_{2}, 1.1$ EGTA, 20 TEA-Br, 0.5 4-AP, 10 HEPES. The $\mathrm{pH}$ was adjusted to 7.24 with $\mathrm{CsOH}$; osmolality was $323 \mathrm{mOsm} / \mathrm{kg}^{-1}$; osmolality of the respective external solution was adjusted to $320 \mathrm{mOsm} / \mathrm{kg}^{-1}$ with sucrose.

All recordings were conducted in a bath volume of $300 \mu \mathrm{l}$ under constant saline flow $(\sim 2 \mathrm{ml} / \mathrm{min})$ at $24^{\circ} \mathrm{C}$ with an Axopatch $200 \mathrm{~B}$ amplifier (Molecular Devices). Data were digitized with a Digidata 1322A (Molecular Devices) at a sampling rate of $10 \mathrm{kHz}$. Before approaching the cell, the offset potential was nulled manually. Upon obtaining a gigaohm seal, fast capacitive artifacts were compensated manually in patch mode at a holding potential of $-70 \mathrm{mV}$. Whole-cell configuration was achieved with gentle negative pressure. Recordings were performed with serial resistances between 10 and $15 \mathrm{M} \Omega$. For voltage-clamp recordings wholecell capacitance was determined and compensated using the Axopatch 200B C-slow dial. Voltage errors caused by series resistance were predicted at $90 \%$, and compensated for by $40-50 \%$ at a time constant of $2 \mu \mathrm{s}$. In voltage-clamp mode input resistance was calculated from the linear slope of the $I-V$ relationship at subthreshold command potentials and subtracted off-line. In current-clamp input resistance was calculated identically but not corrected. $\mathrm{Ca}^{2+}$ currents were induced by voltage steps from -90 to $+20 \mathrm{mV}$ in $10 \mathrm{mV}$ increments from a holding potential of $-90 \mathrm{mV}$. 
Intrinsic excitability of MNs was determined in current-clamp mode by somatic square-pulse current injections. At a resting membrane potential of $-60 \mathrm{mV}$ square-pulse currents of $400 \mathrm{~ms}$ duration were applied in $10 \mathrm{pA}$ increments from -40 to $+90 \mathrm{pA}$.

$\mathrm{MN}$ firing patterns during crawling-like movements were recorded in current-clamp in gap-free acquisition mode. Larval movements were monitored visually. Larval locomotion was not induced but all recordings shown were spontaneously occurring motor patterns. All electrophysiological data were acquired and analyzed with PClamp 10.4 software (Molecular Devices, RRID:SCR_011323).

$\mathrm{MN}$ postsynaptic responses to nicotinic acetylcholine receptor activation were recorded with somatic whole-cell recordings in current-clamp mode. The receptor agonist nicotine $\left(2 \times 10^{-5}\right.$ M; Sigma-Aldrich, cata$\log$ \#N3876; CAS, 54-11-5) was pressure applied focally to MN dendrites with a sharp microelectrode connected to a Picospritzer II (General Valve). Pulse duration was $3 \mathrm{~ms}$ and pressure was set to $20 \mathrm{psi}$.

Calcium imaging. The genetically encoded calcium indicator GCaMP6s (20xUAS-GCaMP6s attP40; Bloomington Stock Center, 42746; RRID: BDSC_42746) was expressed in MNs under the control of RN2-GAL4. An Orca Flash 4.0 LT CMOS camera (C11440-42U; Hamamatsu Photonics) with HOKAWO 2.10 software was used for image acquisition. Exposure times were between 75 and $100 \mathrm{~ms}$. Image series were streamed. Raw data were exported to Microsoft Excel 2010, and $\Delta F / F$ was calculated as previously described (Duch and Levine, 2002; Ryglewski et al., 2017).

Immunocytochemistry. For immunostainings of GFP, the active zone marker bruchpilot (brp) and Dmca1D channels, larvae were dissected in saline, fixed in paraformaldehyde ( $4 \%$ in $0.1 \mathrm{M}$ PBS) for $45 \mathrm{~min}$, washed six times $20 \mathrm{~min}$ in PBS $(0.1 \mathrm{M})$, and 4 times $30 \mathrm{~min}$ in PBS-TritonX $(0.5 \%)$. Then preparations were incubated with primary antibodies (rabbit anti-GFP, 1:400, Invitrogen, A11122, RRID:AB_221569; mouse antiBrp, nc82, DSHB, 1:200, RRID:AB_2314867; goat anti-Dmca1D, 1:400, Santa Cruz Biotechnology, sc-32083, RRID:AB_653056) overnight at $4^{\circ} \mathrm{C}$ in PBS-TritonX $(0.1 \%)$. Specificity of the antibody for Drosophila Dmca1D channels was tested by Western blotting (Fig. 1C), immunocytochemistry on larval muscle (Fig. 1D), Dmca1D ${ }^{X 10}$ mutant versus control embryos (Fig. 1Di), control compared with Dmca1D RNAi knockdown MN somata (Fig. $1 E, F$ ), and $D m c a 1 D^{X 10}$ mutant MNs in genetic mosaics (Fig. 1G,H). Following incubation with primary ABs preparations were washed six times $30 \mathrm{~min}$ in PBS and incubated in secondary ABs (donkey anti-rabbit AlexaFluor 488, Jackson ImmunoResearch, catalog \#711-546-152, RRID:AB_2340619; donkey anti-mouse AlexaFluor 555, ThermoFisher, catalog \#A-31570, RRID:AB_2536180; donkey anti-goat AlexaFluor 647, Jackson ImmunoResearch, catalog \#705-605-147, RRID:AB_2340437; all 1:1000) overnight at $4^{\circ} \mathrm{C}$. Then preparations were washed six times $30 \mathrm{~min}$ in PBS, dehydrated in an ascending ethanol series (50, 70, 90, 100\%, 10 min each), cleared, and mounted in methylsalicylate.

Western blotting. Flies were anesthetized on ice for $10 \mathrm{~min}$. Then brains were removed quickly ( $<30$ s per brain) and immediately homogenized in $85 \mu \mathrm{l}$ sample buffer $(2 \times$ concentrated: $125 \mathrm{~mm} 4 \times$ Tris-HCl/SDS, pH 6.8, 20\% glycerol, 4\% SDS, 20 mu dithiothreitol, $0.001 \%$ bromophenol blue (all Bio-Rad) in $\mathrm{ddH}_{2} \mathrm{O}$ ). Samples were boiled for $3 \mathrm{~min}$, spinned down for $30 \mathrm{~s}$ at $13,000 \mathrm{rpm}$, and stored at $-28^{\circ} \mathrm{C}$ until used. Upon usage, samples were boiled for 3 min directly out of the freezer, spinned down for $1 \mathrm{~min}$ at 13,000 rpm and immediately loaded into gel pockets. The SDS-PAGE gel consisted of a $4 \%$ stacking gel, $\mathrm{pH} 6.8$, and a $5 \%$ running gel, $\mathrm{pH}$ 8.8. Electrophoresis buffer consisted of: $25 \mathrm{~mm}$ Tris base, $190 \mathrm{~mm}$ glycine, and $0.1 \%$ SDS (all Bio-Rad) in $\mathrm{ddH}_{2} \mathrm{O}$. Pockets were loaded with $85 \mu$ l samples containing 10 brains per lane. Band size was determined using Spectra Multicolor High Range Protein Ladder (Life Technologies, 26625), $40 \mu \mathrm{l}$ per lane. The electrophoresis was run at room temperature $\left(\sim 22^{\circ} \mathrm{C}\right)$. Large vertical electrophoresis chambers ( $40 \mathrm{ml}, 15 \times 100 \mu \mathrm{l}$ pockets, with $1.5 \mathrm{~mm}$ thick spacers, Hoefer) guaranteed good separation of protein bands. Proteins were run through the stacking gel at a constant current of $20 \mathrm{~mA}(\sim 1.5 \mathrm{~h})$. Upon reaching the running gel, current was increased to $30 \mathrm{~mA}$ until the bromophenol blue front reached the bottom of the gel $(\sim 5 \mathrm{~h})$. Proteins were transferred onto nitrocellulose membrane (Bio-Rad) overnight at $4^{\circ} \mathrm{C}$ at a constant voltage of $35 \mathrm{~V}$ using transfer buffer ( $25 \mathrm{~mm}$ Tris base, $192 \mathrm{~mm}$ glycine, both Bio-Rad), $15 \%$ methanol (Sigma-Aldrich) in $\mathrm{ddH}_{2} \mathrm{O}$. The next day the nitrocellulose membrane was washed in $\mathrm{ddH}_{2} \mathrm{O}$ for $10 \mathrm{~min}$. Nitrocellulose was washed $3 \times 20 \mathrm{~min}$ in Tris-buffered saline with Tween 20 (TBST; $10 \mathrm{~mm}$ Tris pH 7.5, Biorad; $150 \mathrm{~mm} \mathrm{NaCl}, 0.1 \%$ Tween 20, both Sigma-Aldrich), in $\mathrm{ddH}_{2} \mathrm{O}$, then blocked for $2 \mathrm{~h}$ at room temperature in $10 \%$ milk powder (Sigma-Aldrich) in TBST, and washed again in TBST $3 \times 20 \mathrm{~min}$. Antibodies were prepared in $2.5 \%$ milk powder in TBST and not mixed to avoid cross-reaction. As loading control polyclonal rabbit $\alpha$-heatshock protein 90 (hsp 90) antibody was used 1:1000 (Cell Signaling Technology, catalog \#4874; RRID:AB_2121214). Polyclonal rabbit $\alpha$-GFP IgG antibody (Invitrogen, A-11122; RRID:AB_221569) was used 1:400 to detect GFP-tagged Drosophila Dmca1A voltage gated $\mathrm{Ca}^{2+}$ channel $(\sim 210-240 \mathrm{kDa})$, goat $\alpha$-N-type $\mathrm{Ca}^{2+}$ channel $\alpha 1 \mathrm{~B}$ antibody (L-17; sc-32083, Santa Cruz Biotechnology; RRID:AB_653056) was used 1:400 to detect L-type like Drosophila Dmca1D voltage gated $\mathrm{Ca}^{2+}$ channel ( $\sim 270-280 \mathrm{kDa}$, dependent on splice variants). The nitrocellulose membrane was cut horizontally with a razor blade to separate the part of the membrane where the loading control was expected (at $84 \mathrm{kDa}$ ) from the rest of the gel to avoid antibody cross-reaction. Furthermore, lanes were separated vertically with a razor blade to incubate each lane separately with the desired antibody. Incubation was done in $14 \mathrm{ml}$ Falcon tubes at $4^{\circ} \mathrm{C}$ overnight on a $3 \mathrm{D}$-shaker. Then membranes were washed in TBST for $3 \times 20 \mathrm{~min}$. Secondary antibodies were goat $\alpha$-rabbit IgG antibody, (H+L) HRP conjugate (Millipore, AP307P; RRID:AB_92641) and rabbit $\alpha$-goat IgG antibody, HRP conjugate (Millipore, AP106P; RRID:AB_92411), both used at 1:5000 for $2 \mathrm{~h}$ at room temperature, shaking. Afterward the membrane was rinsed five times with TBST and washed three times for $20 \mathrm{~min}$ with TBST. Band detection was done after 5 min incubation using Immobilon Western Chemiluminescent HRP Substrate (Millipore, WBKLS0500). For detection with a chemiluminescence detection system (Fusion-SL 4.2) and Fusion Bio-1D software (both PEQLAB Biotechnologies) all pieces were reassembled in a transparent sheet protector so that the original membrane was restored.

Image acquisition and processing. Immunolabeled whole-mount preparations were scanned with a Leica SP8 confocal laser scanning microscope with a $40 \times$ oil-immersion lens (NA 1.2). Confocal setting for AlexaFluor 488, 555, and 647 dyes were as follows: argon laser excitation at 488 and detection between 500 and $530 \mathrm{~nm}$. Solid-state laser excitation at $561 \mathrm{~nm}$ and detection between 570 and $600 \mathrm{~nm}$. Helium-neon laser excitation at 633 and detection between 640 and $690 \mathrm{~nm}$. AlexaFluor 488 and 647 were excited and scanned simultaneously, but AlexaFluor 555 was scanned separately to avoid signal crosstalk (SP8 sequential scan mode). Laser and detector settings were switched after each frame. Images were processed with AMIRA4.1 (RRID:SCR_014305), ImageJ (RRID:SCR_003070), and Corel Draw X7 (RRID:SCR_014235) software.

Experimental design and statistical analysis. Analysis was conducted with Microsoft Excel 2010 and SPSS Statistics 22 (RRID:SCR_002865). Using the Shapiro-Wilk test, datasets were considered normally distributed at $p>0.1$ and presented as mean and SD. Parametric testing was used for statistical comparison of experimental groups (Students $t$ test for comparison of two groups, and ANOVA with LSD and/or NewmanKeuls post hoc testing for comparisons of $>2$ groups). If the criterion for normal distribution was not met, data were presented as boxplots (medians and quartiles in boxes and $10 \%$ and $90 \%$ values as error bars). Kruskal-Wallis ANOVA was used for statistical analysis of nonparametric data. Mann and Whitney $U$ test was used for pairwise comparison of two groups, and for post hoc testing following detection of statistical significance with the Kruskal-Wallis test. Significance was accepted at ${ }^{\star} p<0.05,{ }^{* *} p<0.01,{ }^{* *} p<0.001$. Sample size was not computed a priori because no information on expected effect sizes was available, and we did not use vertebrate animals. Instead, for key findings we report the level of significance, the variance, and the numbers of experiments, which together provide information on statistical power. In some cases we also provide information about effect sizes. Effect size for normally distributed data was calculated as Cohen's $d$ (difference between the means of the experimental and the control group divided by the pooled $\mathrm{SD})$. For nonparametric data effect size $r$ was calculated by dividing the standard score by the square root of sample size (Cohen, 1988). 

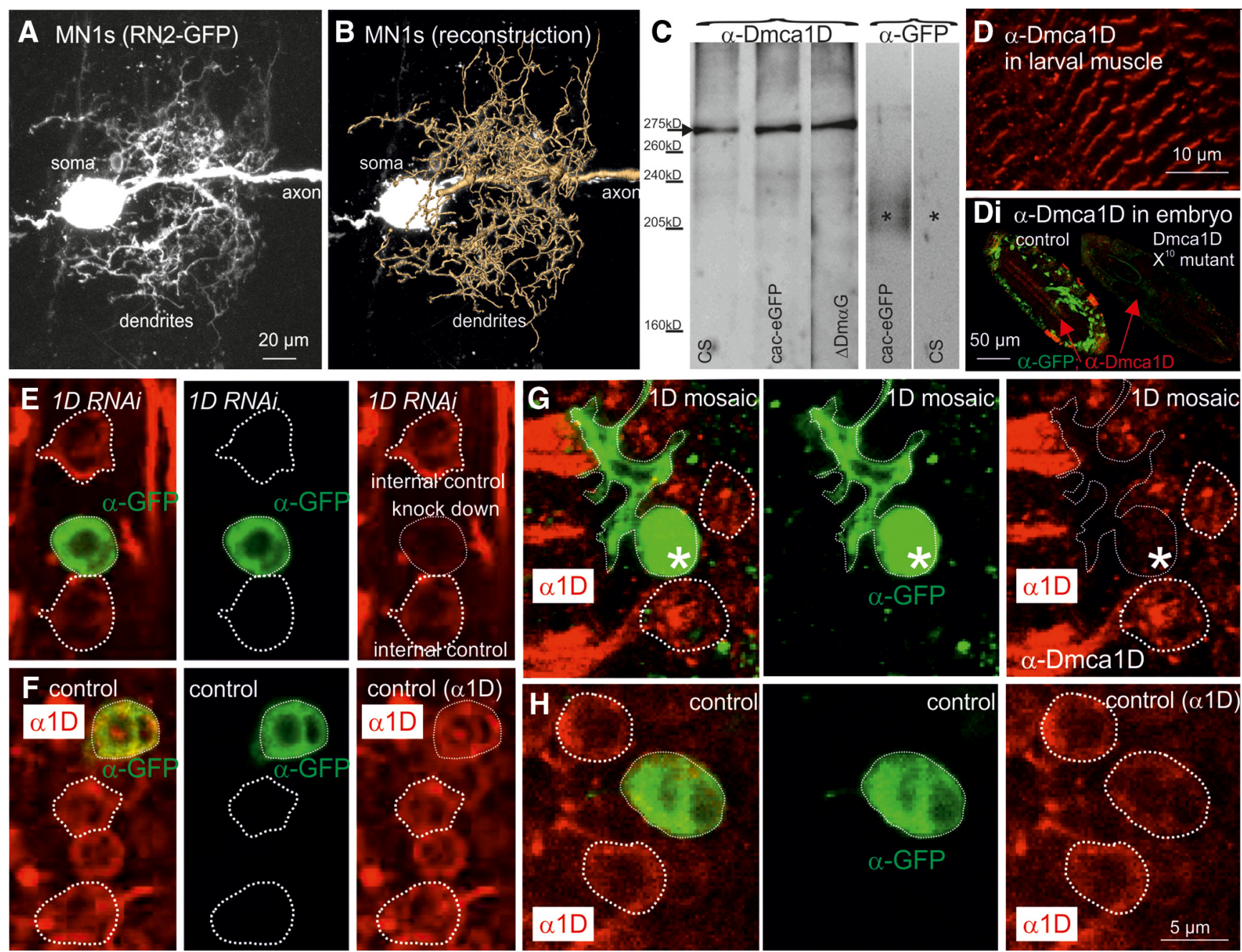

Figure 1. Verification of antibody specificity for Dmca1D channels. $\boldsymbol{A}$, Representative intracellular dye fill of $M N 1 \mathrm{~s}$ in the ventral nerve cord of a third instar larva (B) superimposed with a reconstruction of the dendrites and the initial axonal segment. C, Western blotting with AB sc-32083 against brain homogenate of Canton S controls, Dm $\alpha G-n u l /$ mutants, and Dmca1A-null mutants with pan-neuronal expression of Dmca1A-GFP each yielded a single band at the predicted molecular weight for Dmca1D channels (274 kDa). By contrast $\alpha$-GFP against brain homogenate of Dmca1A-GFP knock-in animals yielded a signal at $\sim 210-240 \mathrm{kDa}$ (see asterisks, predicted size for Dmca1A) but not for head homogenate from Canton S. D, AB sc-32083 labels Dmca1D channels (red) in larval muscle. Di, AB sc-32083 labeled CNS in heterozygous Dmca 1D ${ }^{x 10}$ mutant embryos (left) which were balanced over Cy0 P\{Act-GFP\} and thus GFP-positive. By contrast no $\alpha$-Dmca1D label and no GFP were present in homozygous Dmca1D ${ }^{x 10}$ mutant embryos (right). $\boldsymbol{E}$, Mosaic expression of GFP together with Dmca1D RNAi revealed no Dmca1D immunolabel in somata of GFP-positive knockdown MNs (encircled by narrow dotted line), but clear label in internal control MN somata (encircled by dotted white lines). $\boldsymbol{F}$, By contrast, mosaic expression of GFP without RNAi showed clear Dmca1D immunolabel in all MN somata, with GFP (narrowly dotted lines) and without GFP expression (dotted white lines). G, H, Mosaic analysis with a repressible cell marker (MARCM) was used to generate $D m c a 1 D^{X 10}$ (null) mutant, GFP labeled MNs in an otherwise heterozygous and unlabeled background. G, Single optical section through a representative GFP labeled (green) Dmca $1 D^{X 10}$ mutant MN (soma and primary neurite only). Dmca1D immunocytochemistry (red) in the same optical section reveals numerous immunopositive processes, but no label in the $D m c a 1 D^{X 10}$ mutant MN (outlined by narrowly dotted white line, asterisk). By contrast, other MN somata (outlined by dotted white circles) exhibit Dmca1D-immunopositive label. $\boldsymbol{H}$, To control for potential artificial effects of GFP expression, mosaic GFP expression (green) was combined with Dmca1D immunostaining (red). GFP-positive MN somata (narrowly dotted white line) showed similar Dmca1D-immunopositive signal compared with GFP-negative MN somata.

\section{Results}

Dmca1D channels localize along $\mathrm{MN}$ axons and to patches of MN dendrites

Dmca1D underlies L-type like $\mathrm{Ca}^{2+}$ current that can be recorded from the somata of larval RP2 (MNIs) and aCC (MN1b) MNs (Worrell and Levine, 2008). However, the localization of Dmca1D channels has not been tested directly in invertebrate neurons. Before analyzing Dmca1D localization in third instar larval MNs with extensively branched dendrites $(\sim 3000 \mu \mathrm{m}$ total length; Fig. $1 A, B)$, we confirmed specificity of a commercially available polyclonal antibody (see Materials and Methods) for Dmca1D channels by Western blotting (Fig. 1C). Brain homogenate from wild-type flies yielded a single band at the predicted size of Dmca1D protein (274 kDa; Fig. 1C, $\alpha$-Dmca1D, left lane).
No bands were detected at the predicted sizes for the other two Drosophila VGCCs, namely Dm $\alpha$ G (T-type like, $350 \mathrm{kDa}$ ) and Dmca1A (P/Q, N-type like, 210 kDa; Ryglewski et al., 2012). Moreover, the single band at the predicted size of DmcalD (274 $\mathrm{kDa}$ ) was also present in brain homogenate from Dm $\alpha$ G-null mutants (Fig. $1 C, \alpha$-Dmca1D, right lane). A knock-in scheme, pan-neuronal GFP-tagged UAS-DmcalA transgene expression in a Dmca1A-null mutant background (Kawasaki et al., 2002), excluded possible detection of Dmca1A. Brain homogenate from this group was run separately with putative $\alpha$-DmcalD and $\alpha$-GFP AB. Again, the putative $\alpha$-Dmca1D AB yielded a single band at $274 \mathrm{kDa}$ (Fig. 1C, $\alpha$-Dmca1D, middle lane). By contrast, $\alpha$-GFP yielded a signal at the predicted weight for DmcalA ( $\sim 210-240 \mathrm{kDa}$; Fig. 1C, $\alpha$-GFP, left lane, asterisk), but no signal 

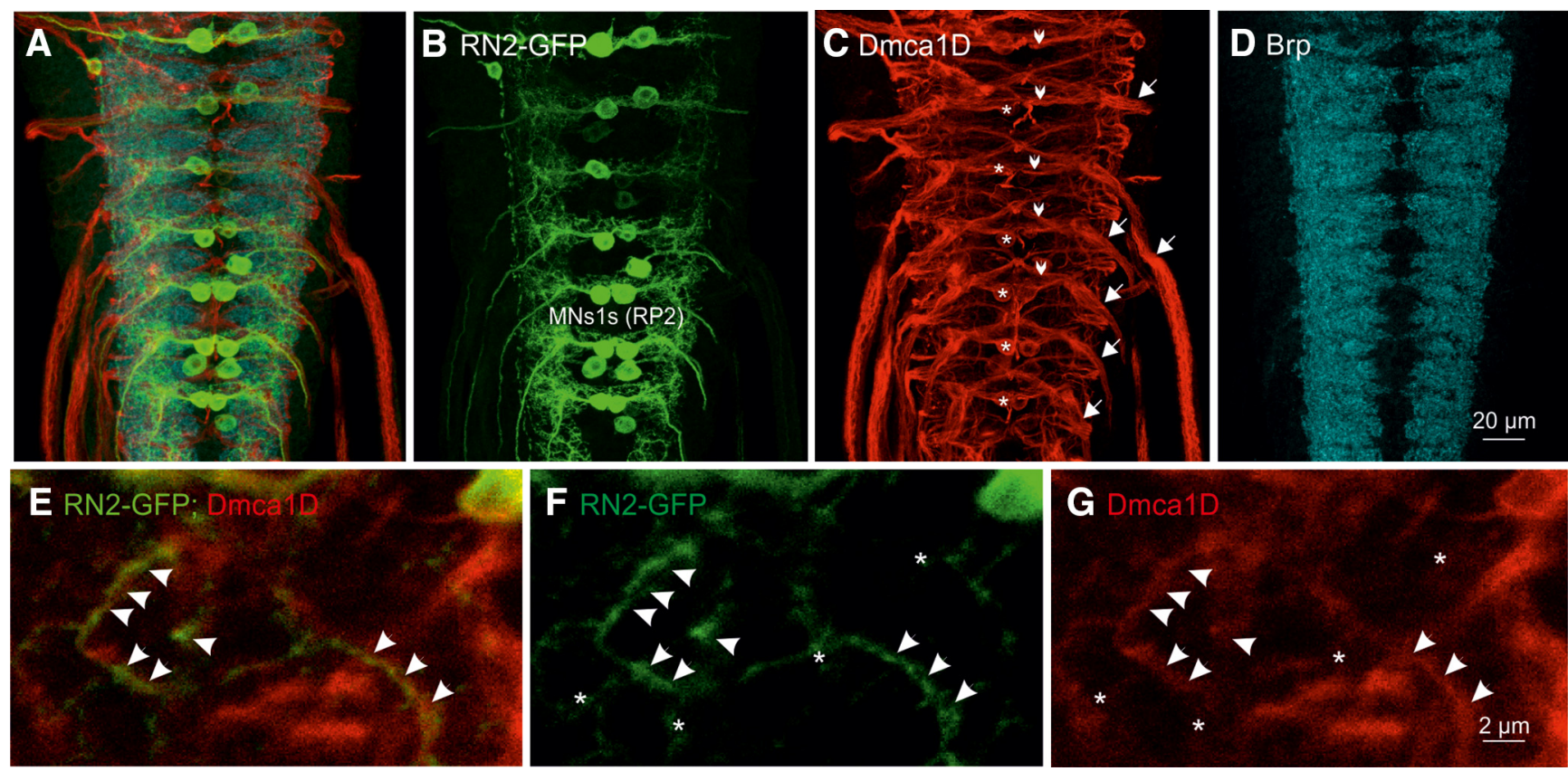

Figure 2. Dmca1D channels localize along MN axons and to patches of MN dendrites. $\boldsymbol{A}-\boldsymbol{D}$, Triple label $(\boldsymbol{A})$ of ventral nerve cord with GFP expression in MNs MN1b and MNIs ( $\boldsymbol{B}$, green) under the control of RN2-GAL4, $\alpha$-Dmca1D immunolabel (C, red), and $\alpha$-Brp immunolabel as a neuropil marker ( $\boldsymbol{D}$, blue). Dmca1D localization (red) was detected in MN somata (asterisks), segmental nerve roots (arrows), and in axon commissures (arrowheads). $\boldsymbol{E}-\boldsymbol{G}$, Selective magnifications indicate Dmca1D ( $\boldsymbol{G}$, red) localization (arrows) to patches of MN dendrites ( $\boldsymbol{F}$, green). $\boldsymbol{F}, \boldsymbol{G}$, Asterisks indicate dendrites without Dmca1D label.

in brain homogenate from Canton S controls. This excluded detection of Dmca1A channels, although a previous study suggested this $\mathrm{AB}$ to detect DmcalA (Astorga et al., 2012).

Four additional lines of evidence for $\mathrm{AB}$ specificity were provided by immunocytochemistry. First, this $\mathrm{AB}$ yielded prominent immunolabel in larval muscle (Fig. 1D), which is known to express Dmca1D Ca ${ }^{2+}$ channels (Gielow et al., 1995; Singh and Wu, 1999). Second, the $\mathrm{AB}$ yielded immunopositive label in the CNS of heterozygous Dmca1D ${ }^{X 10}$ mutant embryos, which were balanced over CyO P $\{$ Act-GFP $\}$, and thus also GFP-positive (Fig. 1Di, left). By contrast no $\alpha$-Dmca1D label and no GFP were present in homozygous Dmca1D ${ }^{X 10}$ mutant embryos (Fig. $1 D i$, right). Third, mosaic RNAi knockdown of Dmca1D in subsets of MNs (see Materials and Methods) reduced the intensity of immunolabeling with this $\mathrm{AB}$ in MNs expressing DmcalD-RNAi and GFP compared with internal control MNs without transgene expression (Fig. $1 E$ ). To rule out possible artificial effects of GFP on DmcalD expression, we also created mosaic GFP expression in subsets of MNs without any RNAi. There, all MN somata revealed similar Dmca1D-immunopositive signal (Fig. $1 F$ ), independent of GFP expression. Finally, evidence for $\mathrm{AB}$ specificity was provided by the absence of label in Dmca1D ${ }^{X 10}$-null mutant MNs. Because Dmca1D-null mutants are embryonic lethal, we used the MARCM technique (Lee and Luo, 2001) to create singled-out Dmca1D ${ }^{\mathrm{X} 10}$-null mutant but GFPpositive $\mathrm{MNs}$ in an otherwise heterozygous background (see Materials and Methods). No detectable AB label was found in GFPpositive null mutant MNs (Fig. $1 G$ ), but neighboring heterozygous neurons were labeled (Fig. 1G). By contrast, controls for mosaic GFP expression that did not carry the Dmca1D ${ }^{X 10}$ mutation showed Dmca1D immunolabel in GFP-positive and in GFP-negative neurons $($ Fig. $1 H$ ). Together, these data provided multiple lines of evidence that this antibody was specific for Dmca1D channels.

Triple immunolabeling of larval RP2 and aCC MNs with $\alpha$-GFP (RN2-GFP), neuropil regions with the active zone marker, $\alpha$-Brp, and $\alpha$-Dmca1D revealed localization of DmcalD channels to multiple neuronal compartments (Fig. 2; 15 animals tested). Continuous Dmca1D label was found along all MN axons in all segmental nerve roots (Fig. $2 C$, white arrows). Dmca1D was also detected in axons of other neurons, which projected in CNS commissures or through segmental nerve roots (Fig. 2C, white arrowheads), indicating axonal Dmca1D localization in multiple different types of neurons. MN somata showed also immunopositive signal for Dmca1D channels (Fig. 2C, white asterisks), though it remained unclear whether somatic label reflected functional L-type channels in the membrane, or channel production. As suggested by previously published voltage-clamp recordings (Worrell and Levine, 2008), patches of Dmca1D label were also detected in $\mathrm{MN}$ dendrites (Fig. 2E-G, white arrowheads, asterisks for dendrite without Dmca1D). Therefore, Dmca1D channels localized along larval MN axons and clustered to some dendritic segments of the same MNs. The clustered appearance of Dmca1D to patches of MN dendrites is reminiscent of L-type channel localization in dendrites of spinal MNs (Heckman et al., 2003; Anelli et al., 2007), but the axonal localization has not been reported in vertebrate MNs.

\section{Genetic mosaics allow probing Dmca1D function selectively in identified larval MNs}

A general problem in addressing cell intrinsic ion channel function during network activity is that bath applied pharmacological blockers may affect all neurons in the network. Therefore, we used Drosophila genetics to target Dmca1D RNAi together with GFP as a reporter to subsets of larval crawling MNs (flippase strategy, see Materials and Methods). The comparison of Dmca1D immunolabel intensities in MN somata with and without RNAi (see above, 10 animals) indicated that Dmca1D-immunopositive label was reduced in MNs with GFP and RNAi expression (Fig. 1E, right), but not in internal control MNs in the same preparation (Fig. 1E, right). By contrast, in control animals with mosaic GFP but no RNAi expression, GFP-positive and GFP-negative MNs displayed similar Dmca1D immunolabel intensities (Fig. 1F; 


\section{A L-type like current}

\section{B I/ V - relationship C Imax at $0 \mathrm{mV}$}
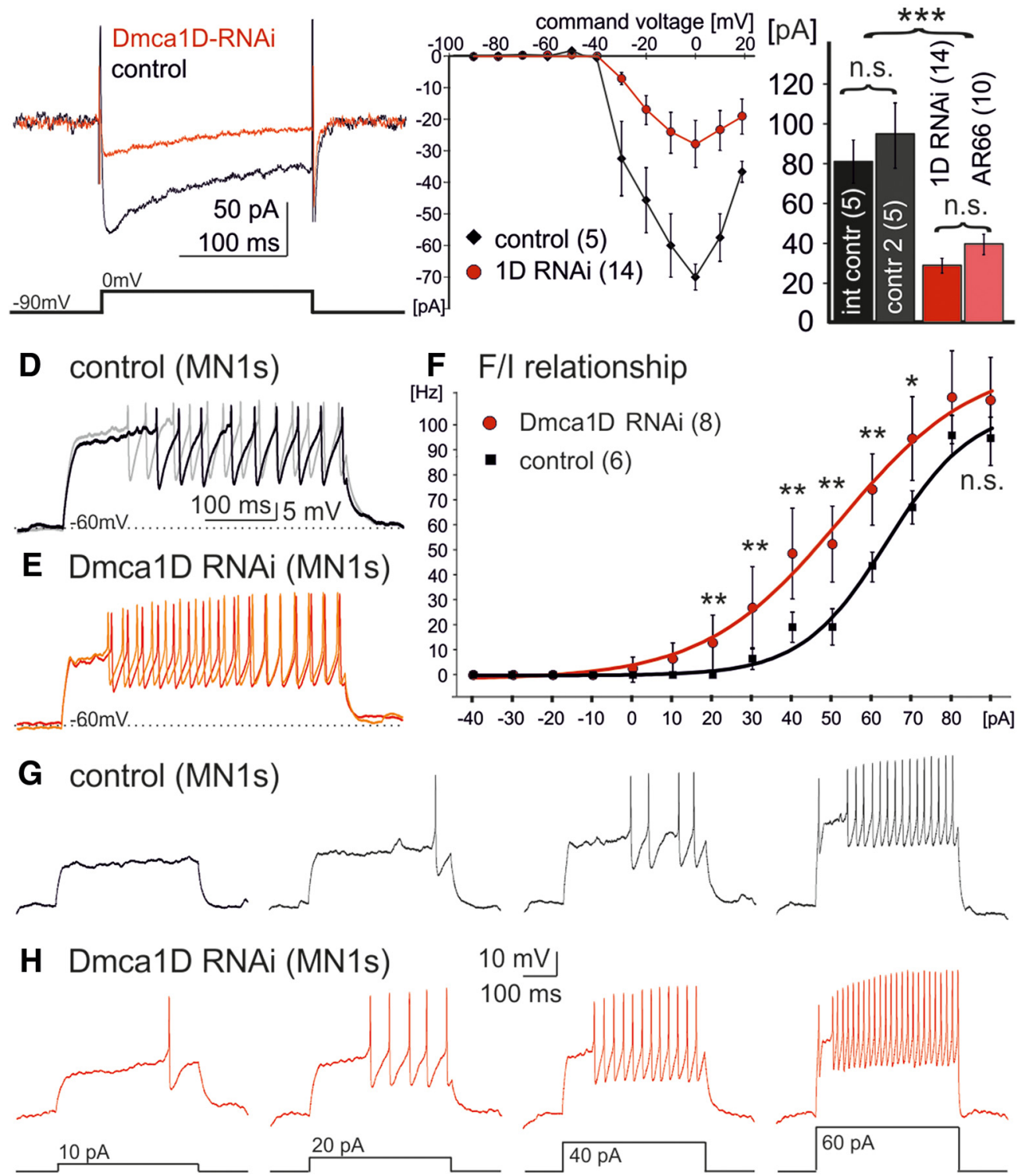

Figure 3. Dmca1D-mediated L-type current decreases MN firing responses to somatic current injection. $\boldsymbol{A}$, Representative somatic voltage-clamp recording of a control MN-1s (Na ${ }^{+}$and $\mathrm{K}^{+}$channels blocked) shows L-type like $\mathrm{Ca}^{2+}$ current (black trace) upon stepping from -90 to $0 \mathrm{mV}$ that is reduced upon Dmca1D RNAi expression (red trace). $\boldsymbol{B}$, Current-voltage diagram for average Dmca1D currents as recorded from control MNs (black) and following Dmca1D-RNAi (red). Errorbars depictSD.C, Maximal L-type current $\left(I_{\text {max }}\right)$ in MN-1s s similar in Canton S wild-type MNs (dark gray bar) and in internal control MNs (black bar) in genetic mosaics, but significantly reduced in heterozygous AR66 Dmca 1D mutants (light red bar) and following Dmca1D RNAi expression in subsets of MNs in genetic mosaics (dark red bar). Bars depict mean, error bars SD, and number or recordings in each group is listed in brackets. $\boldsymbol{D}, \boldsymbol{E}$, Representative firing responses to somatic square-pulse current injections of 40 ( $\boldsymbol{D}$, black trace; $\boldsymbol{E}$, red trace) and 50 $\mathrm{pA}(\boldsymbol{D}$, gray trace; $\boldsymbol{E}$, orange trace $)$ for an internal control MN-1s $(\boldsymbol{D})$ and for MN-1s with expression of Dmca1D RNAi $(\boldsymbol{E})$. $\boldsymbol{F}$, Average response firing frequency for square-pulse current injections between -40 and +90 pA in control MN-1s (black) and in MN-1s with Dmca1D RNAi (red). Error bars representSD, asterisks indicate statistical significance. ${ }^{*} p<0.5$, ${ }^{* *} p<0.01,{ }^{* * *} p<0.001$; ANOVA with LSD posthoctesting. $\boldsymbol{G}, \boldsymbol{H}$, Representative firing responses of another control $(\boldsymbol{G})$ and another Dmca1D RNAi $(\boldsymbol{H}) \mathrm{MN}$-1s for current injection amplitudes of 10, 20,40, and 60 pA.

$n=10)$. This indicated that targeted DmcalD RNAi knockdown to subsets of MNs was effective.

Voltage-clamp recordings confirmed that RNAi knockdown of Dmca1D in MNs reduced L-type-like current amplitude by $\sim 70 \%$ compared with internal controls (Fig. $3 A-C$ ). The remaining current was likely not the result of compensatory upregulation of other VGCCs, because blockers for DmcalA (PLTXII) and $\mathrm{Dm} \alpha \mathrm{G}$ (amiloride; Ryglewski et al., 2012) had no effect. In genetic mosaics, non-RNAi-expressing MNs displayed similar maximum current amplitudes at $0 \mathrm{mV}$ as $\mathrm{MNs}$ in control animals for genetic background. By contrast, RNAi-expressing MNs displayed significantly reduced L-type current ampli- tudes, which were similar to those in heterozygous AR66 mutants (Fig. 3C). Therefore, our flippase RNAi scheme provided a useful tool to reduce Dmca1D expression selectively in a subset of identified MNs without affecting other parts of the motor network (but see below for potential indirect effects of genetic knockdown through development).

Dmca1D reduces $\mathrm{MN}$ firing responses to moderate amplitude somatic current injection

Representative MN1s firing responses to somatic square-pulse current injections are depicted in Figure $3 D$ and $E$. For both control (Fig. 3D) and targeted Dmca1D RNAi knockdown (Fig. 

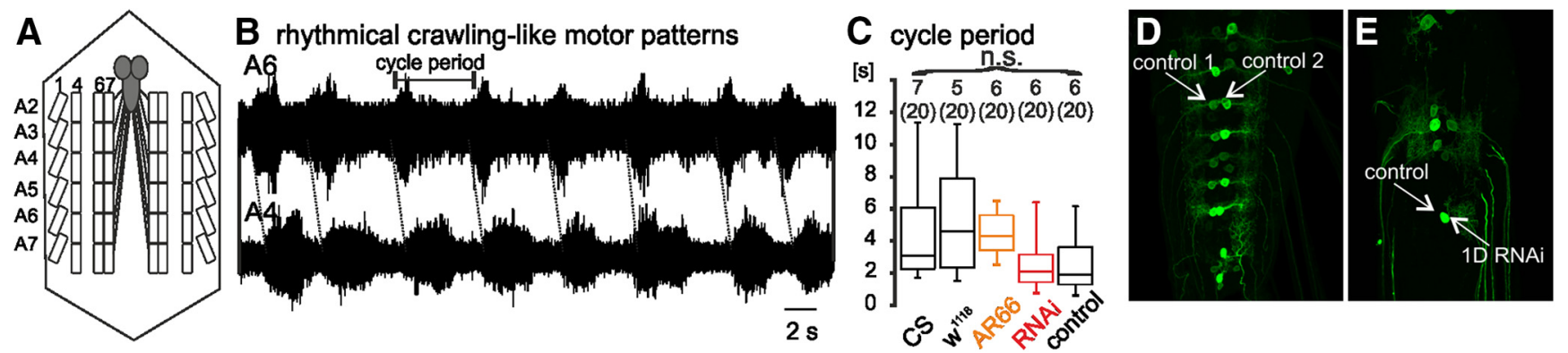

Figure 4. Dmca1D channels enhance MN firing responses to synaptic input from the CPG. $\boldsymbol{A}$, Schematic of neuromuscular system in dissected third instar larva. $\boldsymbol{B}$, Representative extracellular nerve root recordings of crawling-like locomotor activity from abdominal segments 4 and 6. C, Cycle period was statistically similar in controls (CS and w ${ }^{1118}$, left 2 black boxes; GFP in MNs, right black box), in Dmca1D hypomorphic AR66 mutants (orange box), and with Dmca1D RNAi in MNs (red box; Kruskal-Wallis ANOVA, $p=0.37$ ). D, Mosaic GFP expression (green) in a subset of larval MNs. $\boldsymbol{E}$, Mosaic GFP and Dmca1D RNAi in a subset of larval MNs.

$3 E)$ the voltage traces for two current injection amplitudes (40 and $50 \mathrm{pA}$ ) are superimposed. For better visualization additional four voltage responses for current injection amplitudes of 10, 20, 40 , and $60 \mathrm{pA}$ are shown for another control MN1s (Fig. 3G) and another Dmca1D RNAi knockdown (Fig. $3 H$ ). In both control (Fig. $3 D, G$ ) and following targeted DmcalD knockdown (Fig. $3 E, H), M N 1 s$ shows a characteristic biphasic depolarization upon square-pulse current injection that results in a marked delay to the first action potential and was previously described (Choi et al., 2004; Ping et al., 2011). Both the fast depolarization to $\sim-40 \mathrm{mV}$ followed by a slower depolarization to firing threshold and the resulting delay to the first action potential have been attributed to Shal $\left(\mathrm{K}_{\mathrm{v}} 4\right)$ channels, because RNAi knockdown of Shal eliminates the biphasic depolarization and the delay to firing (Schaefer et al., 2010). In agreement with earlier reports (Worrell and Levine, 2008) knockdown of Dmca1D significantly increased the frequency of $\mathrm{MN}$ firing responses to somatic square-pulse current injections (Fig. $3 D-H$ ). This was likely caused by a reduction in the amount of $\mathrm{Ca}^{2+}$ activated $\mathrm{K}^{+}$outward currents (Worrell and Levine, 2008). However, we found increases in $\mathrm{MN}$ firing responses only for current injection amplitudes $(20-70 \mathrm{pA})$, which resulted in moderate firing frequencies of $10-90 \mathrm{~Hz}$ (Fig. $3 F-H)$. But note that DmcalD RNAi knockdown did not cause significant increases of MN firing frequencies in responses to somatic current injection amplitudes that evoked locomotion-like firing frequencies (Fig. $3 F ;>90 \mathrm{~Hz}$ at current amplitudes $\geq 80 \mathrm{pA}$; see Fig. $7 G-J$ ). In square-pulse protocols, we did not increase the amplitude of injected current $>90 \mathrm{pA}$ because this often resulted in unstable recordings from the small somata of larval Drosophila MNs. However, ramp current injections that resulted in peak firing frequencies $>100 \mathrm{~Hz}$ showed decreased firing frequencies upon blockade of Dmca1D (see Fig. 7D, G-K). Therefore, a reduction of Dmca1D channels increased $\mathrm{MN}$ responsiveness to somatic current injections in the lower frequency range $(<90 \mathrm{~Hz})$, did not affect $\mathrm{MN}$ firing rates in medium range locomotion-like frequencies $(90-110 \mathrm{~Hz})$, but decreased maximum intraburst firing frequencies $(>120 \mathrm{~Hz}$; see Fig. 7G,I). However, somatic current injections likely did not account for $\mathrm{MN}$ firing responses to normal network input. Therefore, we next recorded MNs in situ during crawling-like locomotor patterns in semi-intact preparations (Figs. 4, 5).

Dmca1D is not required for gross motor coordination during crawling

Larval forward crawling is characterized by rhythmical waves of segmental MN bursts that propagate from the posterior to the anterior abdominal segments (Fox et al., 2006; Heckscher et al.,
2012; Kadas et al., 2015). Crawling-like motor patterns were displayed spontaneously by larvae that were dissected along the dorsal midline (Fig. 4A; Kadas et al., 2015). Characteristic delays between motor bursts in posterior and anterior segments could either be recorded extracellularly from segmental nerve roots (Fig. 4B), which contain $\sim 30 \mathrm{MN}$ axons (Hoang and Chiba, 2001), or observed visually under the microscope. Cycle period (onset from 1 burst to the next in the same segment) was statistically similar in wild-type controls, AR66 Dmca1D hypomorphic mutants, targeted RNAi in MNs, and genetic controls for the mutant and RNAi strains (Fig. 4C). Similarly, rhythmicity and segmental delays were not significantly different in any of these genotypes. Therefore, Dmca1D channels were not required for coordinated crawling-like motor output, or for the overall central nervous regulation of locomotion speed.

\section{Dmca1D enhances MN excitability during locomotion}

To probe L-type $\mathrm{Ca}^{2+}$ channel function during locomotion specifically in MNs we used our flippase strategy. Dmca1D RNA $i$ was targeted to random subsets of larval RP2 (MN1s) and aCC (MN1b) MNs, to then record either RNAi knockdown or control MNs (Figs. 4D,E, 5). In few instances we were able to conduct dual patch-clamp recordings (data not shown), either from two control MNs (Fig. 4D, GFP-positive aCC MNs), or from a control and a Dmca1D RNA $i$ knockdown aCC MN in the same segment (Fig. 4E, for mosaic expression). The recordings indicated similar intrinsic excitabilities and similar spontaneous activity patterns of sister control aCC MNs $(n=4)$, but different excitabilities $(n=3)$ and different spontaneous activity patterns $(n=1)$ of control versus Dmca1D knockdown aCC MNs (data not shown). However, dual in situ recordings were technically challenging, resulting in insufficient data for thorough analysis, especially because only one mosaic animal displayed typical crawling-like locomotor patterns during dual recording. Therefore, for further analysis we compared individual recordings from $\mathrm{MNs}$ in seven mosaic RNAi knockdown animals and seven genetic controls (Fig. 5A-I).

Representative recordings of a control (Fig. 5A) and a Dmca1D RNAi knockdown MN1s (Fig. 5B) during crawling-like locomotor patterns indicated that RNAi knockdown of L-type like $\mathrm{Ca}^{2+}$ channels reduced MN firing responses to normal CPG activity. Quantification revealed that burst and synaptic drive potential duration were significantly reduced by Dmca1D knockdown (Fig. 5C-E). By contrast, the amplitude of the synaptic drive potential remained unaltered (Fig. $5 C, F$ ). MNs with reduced L-type like $\mathrm{Ca}^{2+}$ current fired significantly fewer action potentials per burst (Fig. $5 G$ ), though the mean intraburst firing rate remained 

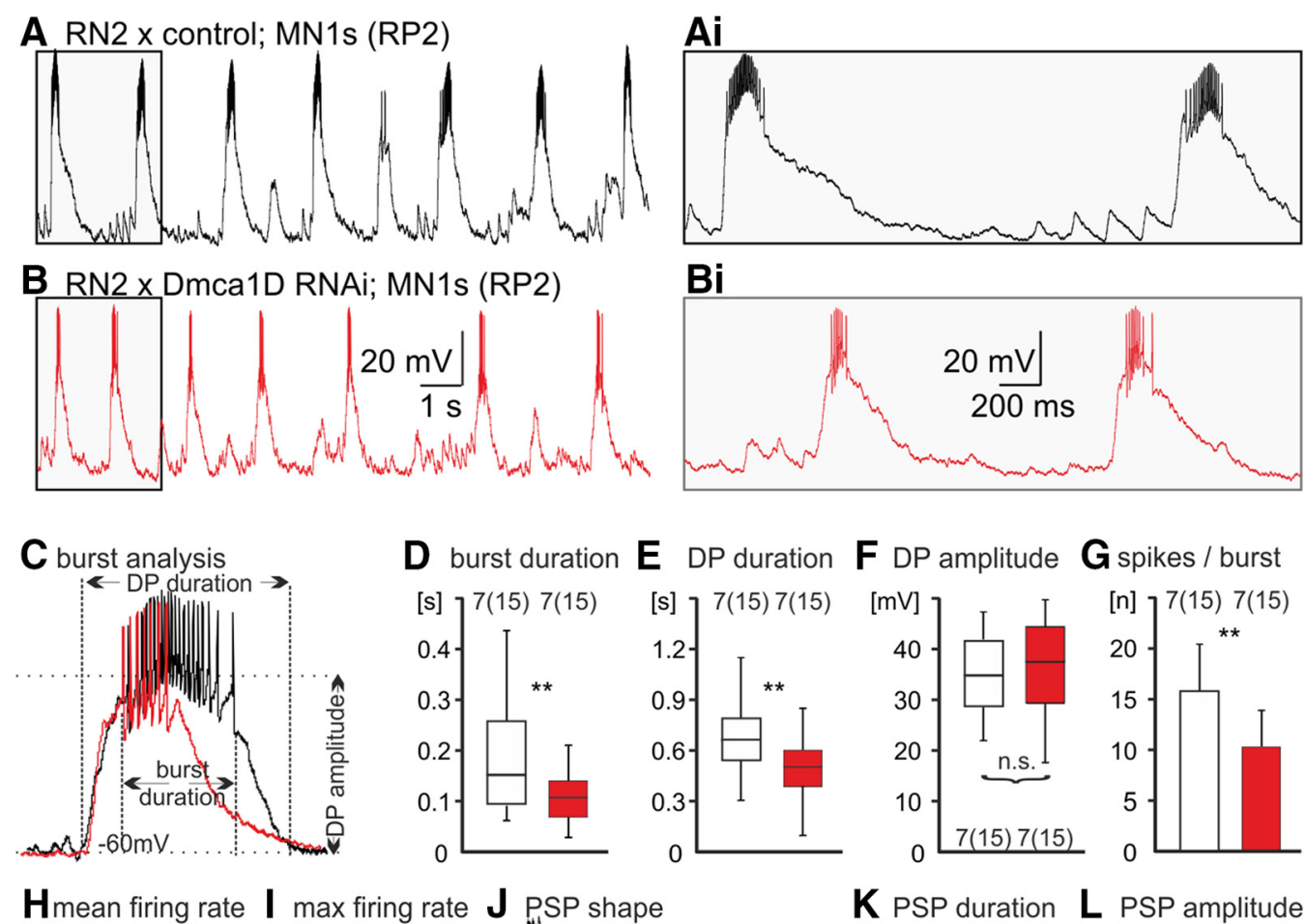

\section{G spikes / burst}
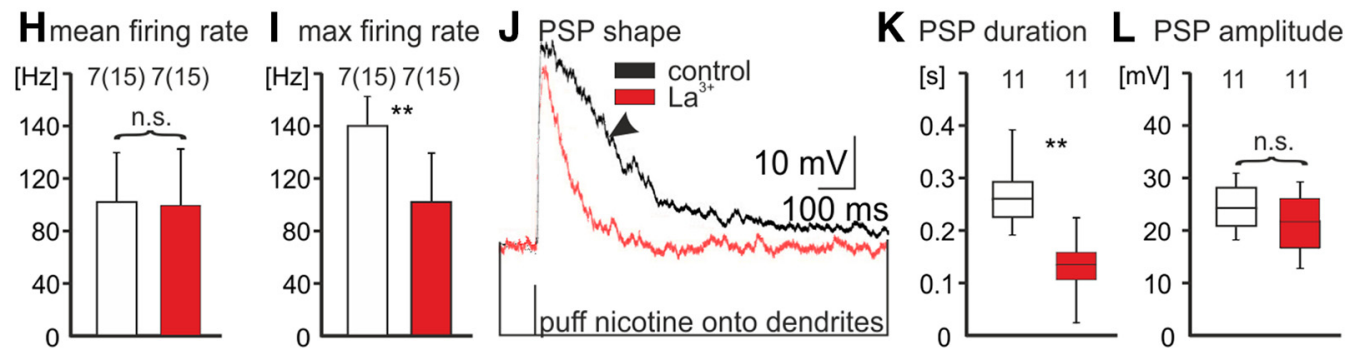

Figure 5. Dmca1D channels prolong MN bursts and increase MN maximum firing rates during crawling. $A, B$, Representative activity patterns of a control $(A$, black trace) and of a Dmca $1 D$ RNAi MN1s (RP2; $\boldsymbol{B}$, red trace) during crawling. The gray shaded areas are enlarged in $\boldsymbol{A i}$ and $\boldsymbol{B i}$, respectively. $\boldsymbol{C}-\boldsymbol{I}$, Quantification of burst parameters $(\boldsymbol{C})$ revealed that selective knockdown of Dmca1D in MN1s (RP2) increased burst duration ( $\boldsymbol{D} ; \boldsymbol{p}<0.01$, effect size $r=0.47)$, drive potential duration $(\boldsymbol{E} ; p<0.01, r=0.52)$, the number of spikes per burst $(\boldsymbol{G} ; p<0.01$, effect size, (ohen $d=1.2)$, and the maximum intraburst firing rate $(\boldsymbol{I} ; \boldsymbol{p}<0.01$, effect size, Cohen $\boldsymbol{d}=1.05)$, but had no effect on drive potential amplitude $(\boldsymbol{F})$ or mean intraburst firing rate $(\boldsymbol{H}) . J$, Representative postsynaptic responses to focal nicotine puffs onto RP2 dendrites before (black trace) and after acute blockade of Dmca1D with La ${ }^{3+}(1 \mu \mathrm{m}$; red trace). Dmca1D block significantly reduced EPSP duration (K; $p<$ 0.01 , effect size $r=0.31$ ) but not EPSP amplitude $(\boldsymbol{L} ; p=0.73)$. Boxes in $\boldsymbol{D}-\boldsymbol{F}$ and $\boldsymbol{K}-\boldsymbol{L}$ depict medians and quartiles, the errors bars show the 10 and $90 \%$ values. Bar diagrams in $\mathbf{G}-\boldsymbol{I}$ show mean \pm SD. Numbers of animals per experimental group are depicted above bars or boxes, and numbers in brackets indicate number of bursts analyzed per animal. Asterisks indicate statistical significance. ${ }^{* *} p<0.01$; Mann- Whitney $U$ test for nonparametric testing; Students $t$ test for normally distributed data.

unaltered (Fig. $5 H$ ). The maximum intraburst firing rates were significantly reduced following targeted DmcalD knockdown (Fig. 5I). Therefore, Dmca1D channels likely affect two aspects of $\mathrm{MN}$ firing patterns during locomotion: they increase drive potential and burst duration, and they increase maximum intraburst firing rates. This likely enhances muscle contraction power for each segmental wave of MN excitation. Similarly, in vertebrates L-type channels enhance muscle force production at a given synaptic drive to MNs (Heckman et al., 2003).

\section{Dendritic Dmca1D channels enhance MN responses to excitatory synaptic input}

In contrast to dendritic L-type channels in vertebrate MNs, Dmca1D localizes to the somatodendritic and to the axonal domains of larval Drosophila MNs (Fig. 1). We next tried to obtain insight as to whether increased MN firing responses to CPG input were caused by axonal or dendritic Dmca1D channels, or both. In vertebrate MNs L-type $\mathrm{Ca}^{2+}$ channels are thought to contribute to PIC, which enhances synaptic drive to dendrites, and thus prolongs MN bursting (Heckman et al., 2003; Hultborn et al., 2013). Given that we observed Dmca1D localization to patches of larval Drosophila MN dendrites (Fig. 2), and that Dmca1D knockdown in postsynaptic MNs shortened burst and drive potential duration (Fig. $5 D, E$ ), we hypothesized dendritic amplification of EPSPs by L-type like $\mathrm{Ca}^{2+}$ channels also in Drosophila MNs. To test this we compared the responses of MNs with normal and reduced Dmca1D current to cholinergic synaptic input (Fig. 5J-L). To circumvent potential developmental effects that may be caused by genetic manipulation through development, we combined focal pressure application of the cholinergic agonist nicotine $\left(2 \times 10^{-5} \mathrm{M}\right)$ with acute pharmacological blockade of Dmca1D with lanthanum $\left(\mathrm{La}^{3+} ; 1 \mu \mathrm{M}\right)$. To prevent indirect effects via the network, we recorded EPSPs in response to nicotine puffs in the presence of the sodium channel antagonist TTX to block action potentials. Focal nicotine application to larval MN dendrites reliably induced EPSPs that could be recorded from the MN soma and typically contained a prolonged shoulder (Fig. 5J, arrowhead). Acute blockade of DmcalD by bath application of $\mathrm{La}^{3+}$ eliminated this shoulder (Fig. 5J, red trace) and significantly shortened the EPSP (Fig. 5J,K). This indicated that dendritic L-type channels normally prolong $\mathrm{MN}$ postsynaptic responses to cholinergic input. 

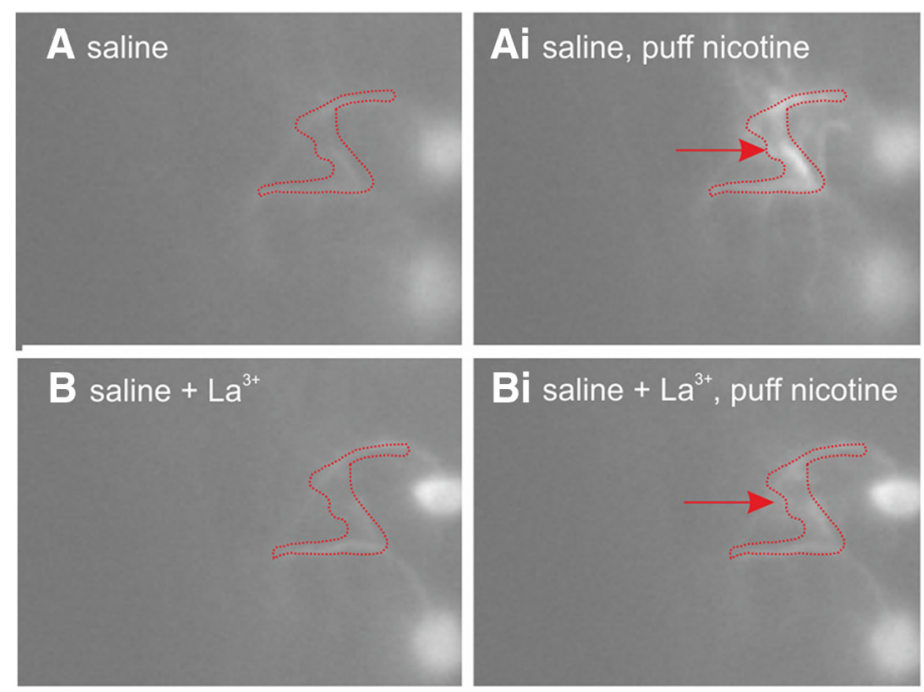
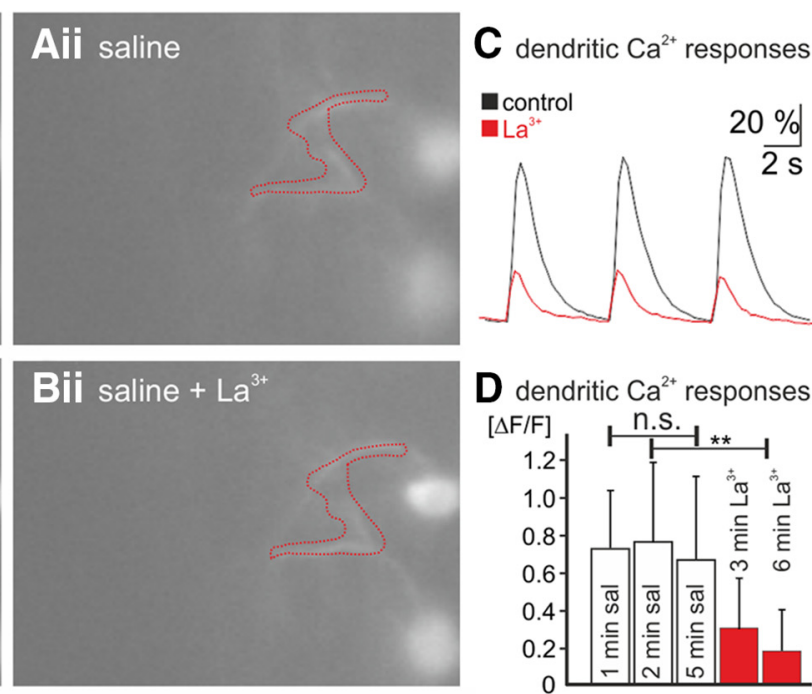

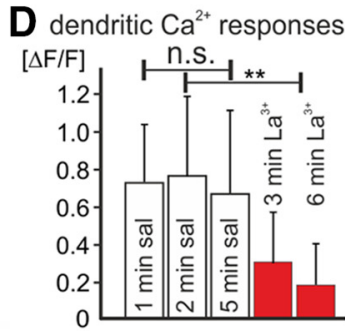

Figure 6. MN Dendritic Dmca1D channels open upon nAChR activation. A-Aii, Representative example of in situ view onto larval MN dendrites with a CMOS camera before $(\boldsymbol{A})$, during $(\boldsymbol{A} \boldsymbol{A}$, red arrow), and after (Aii) focal pressure application of nicotine $\left(2 \times 10^{-5} \mathrm{M}\right.$, red arrow). Red area indicates regions-of-interest. $\boldsymbol{B}$ - $\boldsymbol{B i}$, Same view as in $\boldsymbol{A}$, but with acute pharmacological blockade of Dmca1D by bath application of $\mathrm{La}^{3+}(1 \mu \mathrm{M})$ before $(\boldsymbol{B})$, during (Bi, red arrow), and after (Bii) focal pressure application of nicotine $\left(2 \times 10^{-5} \mathrm{M}\right.$, red arrow). $\boldsymbol{C}$, Representative examples of dendritic $\mathrm{Ca}^{2+}$ signals $(\Delta F / F)$ as taken from red dotted region before (black trace) and after $\mathrm{La}^{3+}$ application (red trace). $\boldsymbol{D}$, Quantification shows that dendritic $\mathrm{Ca}^{2+}$ signals remained unaltered when comparing nAChR activation after 1, 2, or 5 min (white bars, mean and SD), but were reduced significantly ( ${ }^{* *} p<0.01$, ANOVA with LSD post hoc test) after 3 and 6 min in La ${ }^{3+}$ (red bars, mean and SD).

By contrast, EPSP amplitude was not reduced (Fig. 5L). Changes in EPSP amplitude as caused by Dmca1D knockdown were likely masked by a concomitant reduction in $\mathrm{Ca}^{2+}$ activated outward $\mathrm{K}^{+}$current, since we have previously shown that BK channels reduce EPSP amplitude in these MNs (Kadas et al., 2015), and $\mathrm{Ca}^{2+}$ activated dendritic outward conductances are known to reduce the amplitude of prolonged EPSPs in many central neurons (Faber and Sah, 2003). We further confirmed dendritic Dmca1D channel activation upon focal nicotine application by $\mathrm{Ca}^{2+}$ imaging (Fig. 6). Nicotine puffs to larval MN dendrites caused relative increases in local dendritic calcium indicator fluorescence (GCaMP6s) by $60-80 \%$ (Fig. 6A,C). Following pharmacological blockade of Dmca1D channels by bath application of $\mathrm{La}^{3+}$ dendritic calcium signals were decreased to $\sim 20 \%$ (Fig. 6 B, C). No run down in nicotine evoked local dendritic calcium responses was observed within 5 min in saline (Fig. $6 D$ ), but significant reductions were observed already 3 min after bath application of $\mathrm{La}^{3+}$ (Fig. 6D). These results were consistent with a role of dendritically localized Dmca1D channels in boosting synaptic drive to $\mathrm{MN}$ dendrites, and thus prolonging $\mathrm{MN}$ burst duration during locomotion.

Axonal Dmca1D channels enhance maximum MN firing rates Dendritic Dmca1D function did not explain the reduction in maximum firing rates during locomotion upon Dmca1D RNAi in MNs (Fig. $5 I$ ), because synaptic drive potential amplitude remained unaltered (Fig. 5F). Therefore, decreased maximum MN intraburst firing rates in Dmca1D knockdown were not simply a consequence of reduced depolarization amplitude. We have recently shown that BK channels encoded by slowpoke (slo) promote maximum intraburst firing rates by increasing the amplitude of a fast afterhyperpolarization (fAHP), thus promoting de-inactivation of fast $\mathrm{Na}^{+}$channels (Kadas et al., 2015). Similarly, in many fast-spiking mammalian neurons $\mathrm{K}_{\mathrm{v}} 3$ channels augment AP repolarization and the recovery of $\mathrm{Na}^{+}$channels from inactivation (Baranauskas et al., 2003). Based on these reports we hypothesized that axonally localized Dmca1D channels (Fig. 2C) may activate transient BK channels, and thus, indirectly enhance $\mathrm{Na}^{+}$channel de-inactivation during highfrequency firing. Three sets of analysis were conducted to test this hypothesis:

First, we confirmed by $\mathrm{Ca}^{2+}$ imaging that action potentials caused axonal $\mathrm{Ca}^{2+}$ influx (Fig. 7A). Retrograde electrical stimulation of MN axons with a suction electrode placed en passant on the respective motor nerve evoked distinct axonal $\mathrm{Ca}^{2+}$ signals (Fig. $7 \mathrm{~A}$, middle trace). The amplitude of the axonal $\mathrm{Ca}^{2+}$ signals increased with the number of action potentials until saturation at 4-5 action potentials at $100 \mathrm{~Hz}$ (Fig. 7A, bottom trace). MN axonal $\mathrm{Ca}^{2+}$ signals were significantly reduced upon targeted expression of DmcalD RNAi in MNs (Fig. 7Ai). Therefore, axonal Dmca1D channels as detected by immunocytochemistry were functional, not simply a reflection of axonal transport, and mediated activity dependent axonal $\mathrm{Ca}^{2+}$ influx.

Second, if $\mathrm{Ca}^{2+}$ influx through Dmca1D channels was indeed necessary for a BK-mediated fAHP, which in turn enhanced the release of fast $\mathrm{Na}^{+}$channels from inactivation, RNAi knockdown of Dmca1D in MNs should have similar effects on firing rates and fAHP as loss of BK. Therefore, we compared maximum MN intraburst firing frequencies and fAHP amplitudes and durations during locomotor patterns in controls (Fig. $7 B$, top black traces), following selective Dmca1D RNAi in MNs (Fig. $7 B$, middle red traces), and in $s l^{4}$ mutants (Fig. $7 B$, bottom blue traces). Compared with wild-type controls and to internal control MNs in genetic mosaics, maximum intraburst firing rates were significantly decreased in slo mutants (Kadas et al., 2015) and following DmcalD $R N A i$ knockdown in MNs (Fig. $7 B-D$ ). Similarly, compared with controls, the fAHP was smaller (Fig. $7 B, C, E$ ) and slower (Fig. $7 B, C, F)$ in slo mutants and following Dmca1D RNAi knockdown in MNs. Because Dmca1D RNAi did not eliminate all L-type current (Fig. $3 A-C$ ) reductions in fAHP amplitude and maximum firing frequency were not as pronounced as in slo mutants, but statistically significant compared with internal control MNs in mosaic animals $(p<0.01$, unpaired $t$ test) or to wild-type MNs (Fig. $7 D-F)$. This indicated that axonal L-type channels maximized intraburst firing rate by quickly releasing $\mathrm{Na}^{+}$channels from inactivation via a fAHP mediated by BK channel activation. 
However, results from $\mathrm{Ca}^{2+}$ channel knockdown through development must be viewed with caution, because $\mathrm{Ca}^{2+}$ influx may affect multiple aspects of neuronal differentiation (Spitzer, 2006), may cause compensatory changes in the expression of other ion channels (Marder and Goaillard, 2006), and L-type channels can link neural activity and gene expression (Flavell and Greenberg, 2008). Therefore, we next tried to gather additional support for our data by acute pharmacological blockade of Dmca1D. Larval MNs were recorded in current-clamp, and ramp current injections were adjusted to mimic MN crawling bursting patterns (Fig. $7 G$ ). In this setting, acute blockade of DmcalD by bath application of $\mathrm{La}^{3+}(1 \mu \mathrm{M})$ reduced maximum firing rates (Fig. $7 \mathrm{H}, \mathrm{I}$ ) and the amplitude of the fAHP (Fig. $7 \mathrm{H}, \mathrm{J})$, and it increased the duration to maximum fAHP amplitude (Fig. $7 \mathrm{H}, \mathrm{K}$ ). Therefore, results from both sets of experiments, permanent RNAi knockdown and acute blockade, support the hypothesis that Dmca1D channels enhance and sharpen the fAHP amplitude to increase $\mathrm{MN}$ maximum firing rate during locomotion.

\section{Discussion}

A conserved role for L-type $\mathrm{Ca}^{2+}$ channels in augmenting $\mathrm{MN}$ excitability By combining immunocytochemistry with targeted genetic and pharmacological manipulation, calcium imaging, and in situ patch-clamp recordings during locomotorlike behavior, this study shows that L-type $\mathrm{Ca}^{2+}$ current functions in Drosophila MNs to facilitate burst durations and maximum firing rates during rhythmical crawling behavior. Similarly, in vertebrate spinal cord MN burst duration and spike numbers are increased by L-type channels (Heckman et al., 2003), thus indicating a conserved role of VGCCs in augmenting MN excitability from fruit fly larvae (this study) to mammals (Heckman et al., 2003). However, differences exist between species in how $\mathrm{Ca}^{2+}$ channels operate in conjunction with other conductances in mediating this function (Bouhadfane et al., 2013). We find the Drosophila L-type homolog Dmca1D to be localized to the axonal and dendritic compartment of MNs and propose that dendritically located channels increase burst duration whereas axonal channels may promote maximum intraburst firing rates. The proposed dendritic function resembles that of spinal MN L-type channels, whereas the axonal function has not been described before. At present it remains unclear whether axonal and dendritic L-type channels are different splice variants of Dmca1D, possibly with different kinetics. Addressing

MN1s (control)

MN1s (Dmca1D RNAi )
A AP induced axonal calcium signals

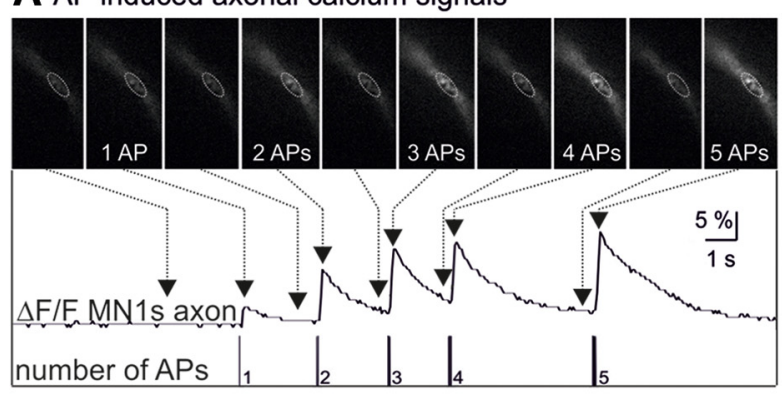

Ai relative change $(\Delta \mathrm{F} / \mathrm{F})$

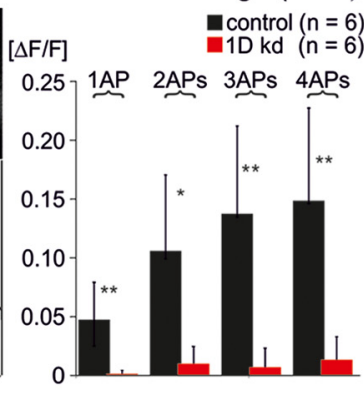

B intraburst spike shape
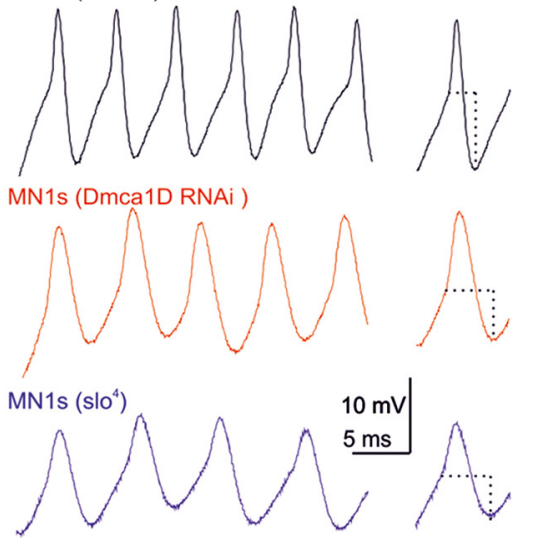

C control, 1D RNAi, slo ${ }^{4}$

D max firing rate
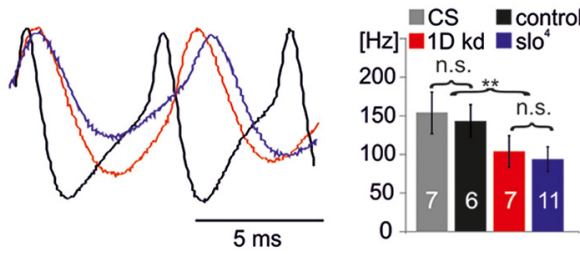

E amplitude of fAHP

$\mathbf{F}$ time to $\min$
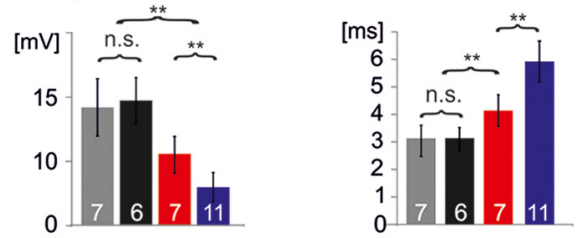

G acute block of Dmca1D

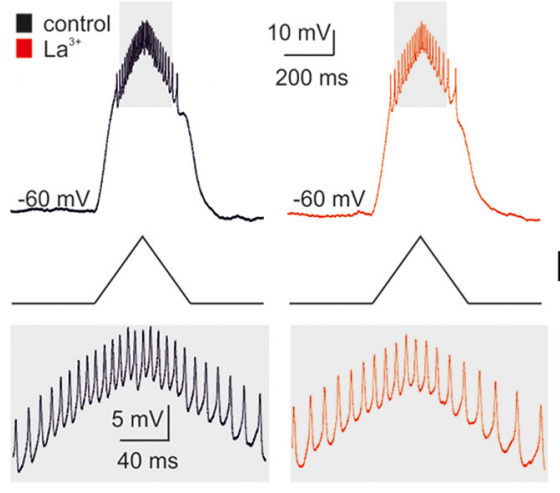

H spike shape

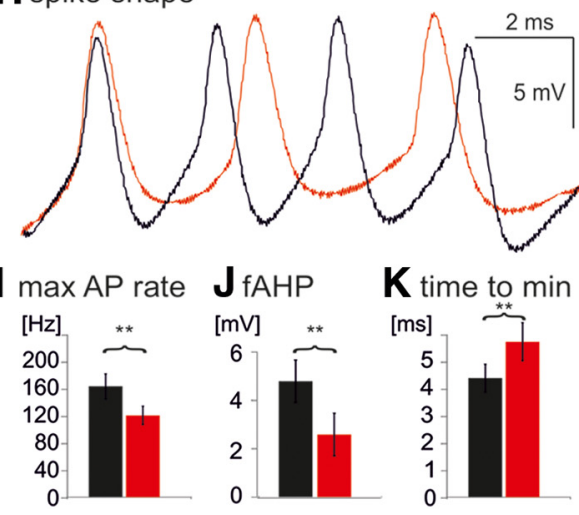

Figure 7. Dmca1D channels cause axonal $\mathrm{Ca}^{2+}$ influx and increase $\mathrm{MN}$ maximum firing rates. $\boldsymbol{A}, \mathrm{Axonal}^{\mathrm{Ca}}{ }^{2+}$ signals as evoked by antidromically evoked MN spikes. Top row shows original imaging data, middle trace relative change $(\Delta F / F)$ in GCaMP6s fluorescence, and bottom trace indicated number of action potentials. Ai, Relative changes $(\Delta F / F)$ in GCaMP6s fluorescence in MN axons in responses to 1,2,3, or 4 action potentials is significantly reduced with expression of Dmca1D RNAi in MNs. $\boldsymbol{B}$, Representative trains of spikes during bursting activity as recorded during crawling-like locomotor activity in a control (top black trace), a Dmca1D RNAi (middle red trace), and a s/0 ${ }^{4}$ mutant MN1s (lower blue trace). Spikes from each trace at maximum firing rate are shown as overlay in $\boldsymbol{C}$. Maximum firing rate $(\boldsymbol{D})$ and fAHP amplitude $(\boldsymbol{E})$ were significantly lower in slo mutant (blue bars) and Dmca1D knockdown MNs (red bars; Cohen's $d$ effect size 1.6, statistical power is 0.84 at the given sample size of 7 and a 95\% confidence interval) compared with the respective controls (gray and black bars), whereas the duration until maximum fAHP amplitude was significantly increased ( $\boldsymbol{F}$; Cohen's $d$ effect size 1.36, statistical power is 0.79 at the given sample size of 7 and a $95 \%$ confidence interval). $\mathbf{G}-\boldsymbol{K}$, Acute blockade of Dmca1D with $\mathrm{La}^{3+}(1 \mu \mathrm{M})$ altered $\mathrm{MN}$ firing responses to ramp current injection that were adjusted to mimic MN1s bursting as observed during crawling. I, Pharmacological blockade of Dmca1D by bath application of $\mathrm{La}^{3+}(1 \mu \mathrm{M})$ significantly reduced maximum intraburst firing rate. J, fAHP amplitude was also significantly reduced and $(\boldsymbol{K})$ the duration to maximum fAHP amplitude was significantly increased upon Dmca1D blockade. Asterisks indicate statistical significance. $\boldsymbol{D}-\boldsymbol{F}:{ }^{*} p<0.05,{ }^{* *} p<0.01$, ANOVA with LSD post hoc test; $\boldsymbol{I} \boldsymbol{K}$ : ${ }^{* *} p<0.01$, paired $t$ test).

these questions by focal voltage-clamp recordings from the soma versus the axon or by protein isoform isolation and analysis from isolated central versus peripheral parts of these MNs was beyond the scope of this study. 


\section{Dendritic Dmca1D channels boost excitatory synaptic drive to $\mathrm{MNs}$}

Spinal MN dendrites can generate PIC, which is either mediated directly by $\mathrm{Ca}^{2+}$ influx through dendritic L-type channels (Heckman et al., 2003), or indirectly by $\mathrm{Ca}^{2+}$-activated nonselective cation currents (Ican; Perrier and Hounsgaard, 1999; Bouhadfane et al., 2013). PIC boosts synaptic drive and thus enhances MN responses to a given synaptic drive (Heckman et al., 2004). Similarly, we found that L-type channels in Drosophila MNs enhance excitatory synaptic input to dendrites. This interpretation is supported by (1) shorter synaptic drive potentials and burst durations during locomotion in MNs with selective RNAi knockdown of Dmca1D, (2) by shorter durations of excitatory postsynaptic responses to focal nicotine puffs to $\mathrm{MN}$ dendrites following selective RNAi knockdown of Dmca1D in MNs, and (3) by reduced dendritic calcium elevations upon focal dendritic nAChR activation following pharmacological block of Dmca1D. Together these data indicate a highly conserved function of L-type channels in enhancing excitatory synaptic input to MN dendrites. In mammals, L-type $\mathrm{Ca}^{2+}$ current enhances $\mathrm{MN}$ firing rates and affects the pattern of MN recruitment (Collins et al., 2001, 2002).

Finally, in spinal MNs L-type current mediated PIC is contingent upon supraspinal aminergic control that facilitates locomotion (Heckman et al., 2003; Perrier and Delgado-Lezama, 2005; Hultborn et al., 2013). Amines also facilitate locomotion in invertebrates (Horvitz et al., 1982; Brembs et al., 2007; Pflüger and Duch, 2011), including Drosophila larvae (Fox et al., 2006), again pointing to conserved molecular strategies for the regulation of motor power output, though direct aminergic modulation of $\mathrm{MN}$ ion channels remains to be investigated in invertebrates.

Axonal Dmca1D channels enhance MN maximum firing rates Evidence for L-type channels in nonsynaptic axonal membrane exists also for hippocampal neurons (Tippens et al., 2008), leech neurons (Beck et al., 2001), rat optic nerve, and spinal dorsal column white matter (Brown et al., 2001, 2003; Ouardouz et al., 2003), though the precise functions remain speculative. Because activity-dependent $\mathrm{Ca}^{2+}$ influx through VGCCs has numerous functions in axonal growth and synaptogenesis, it is difficult to distinguish between developmental and coding functions of axonal $\mathrm{Ca}^{2+}$ channels (Bucher and Goaillard, 2011). Our study provides evidence for axonal $\mathrm{Ca}^{2+}$ influx through L-type channels upon MN firing, thus indicating a coding function for $\mathrm{MN}$ axonal Dmca1D channels. Multiple sets of experiments are in agreement with the hypothesis that $\mathrm{MN}$ axonal L-type channels maximize intraburst firing rate by quickly releasing $\mathrm{Na}^{+}$channels from inactivation via a fAHP mediated by BK channel activation. First, targeted DmcalD RNAi knockdown in subsets of $\mathrm{MNs}$ reduced maximum intraburst firing rates during locomotion (Fig. 5I). Second, when mimicking MN crawling burst shape by somatic current injections, maximum intraburst firing rates were reduced by acute pharmacological blockade of Dmca1D (Fig. 7G,H). Therefore, Dmca1D enhances MN excitability independent of synaptic mechanisms. Third, we have previously reported a reduction in $\mathrm{MN}$ maximum intraburst firing rates upon acute blockade and/or genetic knockdown of slo encoded BK channels (Kadas et al., 2015). Slo increases MN firing rates by mediating a fAHP that augments the release of fast $\mathrm{Na}^{+}$channels from inactivation (Kadas et al., 2015). We now report that RNAi knockdown of DmcalD in MNs mimics the effects of slo on fAHP amplitude and duration (Fig. $7 B-F$ ), thus indicating that slo functions downstream of $\mathrm{Ca}^{2+}$ influx through Dmca1D. However, given that $\mathrm{Ca}^{2+}$ influx through L-type channels may affect multiple aspects of neural differentiation (Spitzer, 2006), or alter transcriptional programs (Flavell and Greenberg, 2008), our data from RNAi knockdown of DmcalD must be interpreted with caution. Nonetheless, we judge it unlikely that Dmca1D affects the fAHP in MNs via indirect developmental effects, because acute pharmacological blockade of Dmca1D also decreased the amplitude and increased the duration of the fAHP (Fig. 7G- $J$ ). Therefore, reduced fAHP amplitude and firing rates in MNs were unlikely caused by indirect developmental effects of Dmca1D knockdown, but rather by reduced acute slo activation because of reduced activity-dependent $\mathrm{Ca}^{2+}$ influx.

In summary, our data indicate a conserved role for L-type VGCCs in enhancing MN excitability. Although synaptic input amplification by dendritic L-type channels exists in spinal MNs (Heckman et al., 2003) and in insect MNs (this study), we found no evidence for PIC in Drosophila MNs. Given that spinal MN dendrites extend spatially by approximately a factor 10-20 further than larval Drosophila MNs (Duch and Ryglewski, 2016), we speculate that PIC might be a specialization of the immensely far reaching vertebrate MN dendrites (Heckman et al., 2003, 2004). In addition, our data indicate that $\mathrm{Ca}^{2+}$ influx through axonal L-type channels is required in Drosophila MNs to support highfrequency firing through BK channel-mediated fAHP and $\mathrm{Na}^{+}$ channel de-inactivation. Therefore, L-type channels subserve distinctly different functions in different neuronal compartments, but both functions cooperate in increasing $\mathrm{MN}$ firing rates during locomotion. BK channel activation by axonal $\mathrm{Ca}^{2+}$ influx through VGCCs is also required for maximum firing rates of other central neurons, including CA1 pyramidal neurons $(\mathrm{Gu}$ et al., 2007), indicating that similar mechanisms are used by different types of central neurons. However, this axonal mechanism does not seem to exist in vertebrate MNs and might well be a unique feature of unmyelinated invertebrate motor axons. We suggest that facilitation of MN excitability by L-type channels is an old strategy, but interactions with other conductances and strategic placement to specific motoneuronal compartments seem well adapted to the distinctly different requirements in morphologically different nervous systems of different species.

\section{References}

Anelli R, Sanelli L, Bennett DJ, Heckman CJ (2007) Expression of L-type calcium channel $\alpha_{1}-1.2$ and $\alpha_{1}-1.3$ subunits on rat sacral motoneurons following chronic spinal cord injury. Neuroscience 145:751-763. CrossRef Medline

Astorga G, Härtel S, Sanhueza M, Bacigalupo J (2012) TRP, TRPL and cacophony channels mediate $\mathrm{Ca}^{2+}$ influx and exocytosis in photoreceptors axons in Drosophila. PLoS One 7:e44182. CrossRef Medline

Baranauskas G, Tkatch T, Nagata K, Yeh JZ, Surmeier DJ (2003) Kv3.4 subunits enhance the repolarizing efficiency of Kv3.1 channels in fast-spiking neurones. Nat Neurosci 6:258-266. CrossRef Medline

Beck A, Lohr C, Deitmer JW (2001) Calcium transients in subcompartments of the leech Retzius neuron as induced by single action potentials. J Neurobiol 48:1-18. CrossRef Medline

Bouhadfane M, Tazerart S, Moqrich A, Vinay L, Brocard F (2013) Sodiummediated plateau potentials in lumbar motoneurons of neonatal rats. J Neurosci 33:15626-15641. CrossRef Medline

Brembs B, Christiansen F, Pflüger HJ, Duch C (2007) Flight initiation and maintenance deficits in flies with genetically altered biogenic amine levels. J Neurosci 27:11122-11131. CrossRef Medline

Brown AM (2003) A modeling study predicts the presence of voltage gated $\mathrm{Ca}^{2+}$ channels on myelinated central axons. Comput Methods Programs Biomed 71:25-31. CrossRef Medline

Brown AM, Westenbroek RE, Catterall WA, Ransom BR (2001) Axonal L-type $\mathrm{Ca}^{2+}$ channels and anoxic injury in rat CNS white matter. J Neurophysiol 85:900-911. Medline

Bucher D, Goaillard JM (2011) Beyond faithful conduction: short-term dynamics, neuromodulation, and long-term regulation of spike propagation in the axon. Prog Neurobiol 94:307-346. CrossRef Medline 
Choi JC, Park D, Griffith LC (2004) Electrophysiological and morphological characterization of identified motor neurons in the Drosophila third instar larva central nervous system. J Neurophysiol 91:2353-2365. CrossRef Medline

Cohen J (1988) Statistical power analysis for the behavioral sciences. New York: Routledge.

Collins DF, Burke D, Gandevia SC (2001) Large involuntary forces consistent with plateau behavior in human motoneurons. J Neurosci 21:40594065. Medline

Collins DF, Burke D, Gandevia SC (2002) Sustained contractions produced by plateau-like behavior in human motoneurons. J Physiol 538:289-301. CrossRef Medline

Dietzl G, Chen D, Schnorrer F, Su KC, Barinova Y, Fellner M, Gasser B, Kinsey K, Oppel S, Scheiblauer S, Couto A, Marra V, Keleman K, Dickson BJ (2007) A genome-wide transgenic RNAi library for conditional gene inactivation in Drosophila. Nature 448:151-156. CrossRef Medline

Duch C, Levine RB (2002) Changes in calcium signaling during postembryonic dendritic growth in Manduca sexta. J Neurophysiol 87:1415-1425. CrossRef Medline

Duch C, Ryglewski S (2016) Structure and function of neuronal dendrites. e-Neuroforum 7:71-81. CrossRef

Eberl DF, Ren D, Feng G, Lorenz LJ, Van Vactor D, Hall LM (1998) Genetic and developmental characterization of Dmca1D, a calcium channel alphal subunit gene in Drosophila melanogaster. Genetics 148:1159-1169. Medline

Faber ES, Sah P (2003) Calcium-activated potassium channels: multiple contributions to neuronal function. Neuroscientist 9:181-194. CrossRef Medline

Flavell SW, Greenberg ME (2008) Signaling mechanisms linking neuronal activity to gene expression and plasticity of the nervous system. Annu Rev Neurosci 31:563-590. CrossRef Medline

Fox LE, Soll DR, Wu CF (2006) Coordination and modulation of locomotion pattern generators in Drosophila larvae: effects of altered biogenic amine levels by the tyramine beta hydroxlyase mutation. J Neurosci 26: 1486-1498. CrossRef Medline

Fujioka M, Lear BC, Landgraf M, Yusibova GL, Zhou J, Riley KM, Patel NH, Jaynes JB (2003) Even-skipped, acting as a repressor, regulates axonal projections in Drosophila. Development 130:5385-5400. CrossRef Medline

Gielow ML, Gu GG, Singh S (1995) Resolution and pharmacological analysis of the voltage-dependent calcium channels of Drosophila larval muscles. J Neurosci 15:6085-6093. Medline

Grillner S, Markram H, De Schutter E, Silberberg G, LeBeau FE (2005) Microcircuits in action-from CPGs to neocortex. Trends Neurosci 28:525533. CrossRef Medline

Gu N, Vervaeke K, Storm JF (2007) BK potassium channels facilitate highfrequency firing and cause early spike frequency adaptation in rat CA1 hippocampal pyramidal cells. J Physiol 580:859-882. CrossRef Medline

Hartwig CL, Worrell J, Levine RB, Ramaswami M, Sanyal S (2008) Normal dendrite growth in Drosophila motor neurons requires the AP-1 transcription factor. Dev Neurobiol 68:1225-1242. CrossRef Medline

Heckman CJ, Lee RH, Brownstone RM (2003) Hyperexcitable dendrites in motoneurons and their neuromodulatory control during motor behavior. Trends Neurosci 26:688-695. CrossRef Medline

Heckman CJ, Kuo JJ, Johnson MD (2004) Synaptic integration in motoneurons with hyper-excitable dendrites. Can J Physiol Pharmacol 82:549555. CrossRef Medline

Heckscher ES, Lockery SR, Doe CQ (2012) Characterization of Drosophila larval crawling at the level of organism, segment, and somatic body wall musculature. J Neurosci 32:12460-12471. CrossRef Medline

Hoang B, Chiba A (2001) Single-cell analysis of Drosophila larval neuromuscular synapses. Dev Biol 229:55-70. CrossRef Medline

Horvitz HR, Chalfie M, Trent C, Sulston JE, Evans PD (1982) Serotonin and octopamine in the nematode Caenorhabditis elegans. Science 216:10121014. CrossRef Medline

Hultborn H, Zhang M, Meehan CF (2013) Control and role of plateau potential properties in the spinal cord. Curr Pharm Des 19:4357-4370. CrossRef Medline

Hutchinson KM, Vonhoff F, Duch C (2014) Dscam1 is required for normal dendrite growth and branching but not for dendritic spacing in Drosophila motoneurons. J Neurosci 34:1924-1931. CrossRef Medline

Kadas D, Ryglewski S, Duch C (2015) Transient BK outward current enhances motoneuron firing rates during Drosophila larval locomotion. J Physiol 593:4871-4888. CrossRef Medline
Kawasaki F, Collins SC, Ordway RW (2002) Synaptic calcium-channel function in Drosophila: analysis and transformation rescue of temperature-sensitive paralytic and lethal mutations of cacophony. J Neurosci 22:5856-5864. Medline

Kiehn O (1991) Plateau potentials and active integration in the "final common pathway" for motor behavior. Trends Neurosci 14:68-73. CrossRef Medline

Kiehn O, Kullander K (2004) Central pattern generators deciphered by molecular genetics. Neuron 41:317-321. CrossRef Medline

Kiehn O, Kjaerulff O, Tresch MC, Harris-Warrick RM (2000) Contributions of intrinsic motor neuron properties to the production of rhythmic motor output in the mammalian spinal cord. Brain Res Bull 53:649-659. CrossRef Medline

Lee T, Luo L (2001) Mosaic analysis with a repressible cell marker (MARCM) for Drosophila neural development. Trends Neurosci 24:251254. CrossRef Medline

Marder E, Goaillard JM (2006) Variability, compensation and homeostasis in neuron and network function. Nat Rev Neurosci 7:563-574. CrossRef Medline

Marder E, Bucher D, Schulz DJ, Taylor AL (2005) Invertebrate central pattern generation moves along. Curr Biol 15:R685-R699. CrossRef Medline

Ni JQ, Markstein M, Binari R, Pfeiffer B, Liu LP, Villalta C, Booker M, Perkins L, Perrimon N (2008) Vector and parameters for targeted transgenic RNA interference in Drosophila melanogaster. Nat Methods 5:49-51. CrossRef Medline

Ni JQ, Liu LP, Binari R, Hardy R, Shim HS, Cavallaro A, Booker M, Pfeiffer BD, Markstein M, Wang H, Villalta C, Laverty TR, Perkins LA, Perrimon N (2009) A Drosophila resource of transgenic RNAi lines for neurogenetics. Genetics 182:1089-1100. CrossRef Medline

Ouardouz M, Nikolaeva MA, Coderre E, Zamponi GW, McRory JE, Trapp BD, Yin X, Wang W, Woulfe J, Stys PK (2003) Depolarization-induced $\mathrm{Ca} 2+$ release in ischemic spinal cord white matter involves L-type Ca2+ channel activation of ryanodine receptors. Neuron 40:53-63. CrossRef Medline

Perrier JF, Delgado-Lezama R (2005) Synaptic release of serotonin induced by stimulation of the raphe nucleus promotes plateau potentials in spinal motoneurons of the adult turtle. J Neurosci 25:7993-7999. CrossRef Medline

Perrier JF, Hounsgaard J (1999) Calcium activated nonselective cation current (Ican) in turtle motoneurons. J Neurophysiol 82:730-735. Medline

Pflüger HJ, Duch C (2011) Dynamic neural control of insect muscle metabolism related to motor behavior. Physiology 26:293-303. CrossRef Medline

Ping Y, Waro G, Licursi A, Smith S, Vo-Ba DA, Tsunoda S (2011) Shal/ $\mathrm{K}(\mathrm{v}) 4$ channels are required for maintaining excitability during repetitive firing and normal locomotion in Drosophila. PLoS One 6:e16043. CrossRef Medline

Ren D, Xu H, Eberl DF, Chopra M, Hall LM (1998) A mutation affecting dihydropyridine-sensitive current levels and activation kinetics in Drosophila muscle and mammalian heart calcium channels. J Neurosci 18: 2335-2341. Medline

Ryglewski S, Lance K, Levine RB, Duch C (2012) Ca(v)2 channels mediate low and high voltage-activated calcium currents in Drosophila motoneurons. J Physiol 590:809-825. CrossRef Medline

Ryglewski S, Vonhoff F, Scheckel K, Duch C (2017) Intra-neuronal competition for synaptic partners conserves the amount of dendritic building material. Neuron 93:632-645.e6. CrossRef Medline

Schaefer JE, Worrell JW, Levine RB (2010) Role of intrinsic properties in Drosophila motoneuron recruitment during fictive crawling. J Neurophysiol 104:1257-1266. CrossRef Medline

Singh S, Wu CF (1999) Ionic currents in larval muscles of Drosophila. Int Rev Neurobiol 43:191-220. CrossRef Medline

Spitzer NC (2006) Electrical activity in early neuronal development. Nature 444:707-712. CrossRef Medline

Tippens AL, Pare JF, Langwieser N, Moosmang S, Milner TA, Smith Y, Lee A (2008) Ultrastructural evidence for pre- and postsynaptic localization of Cav1.2 L-type Ca2 + channels in the rat hippocampus. J Comp Neurol 506:569-583. CrossRef Medline

Worrell JW, Levine RB (2008) Characterization of voltage-dependent $\mathrm{Ca}^{2+}$ currents in identified Drosophila motoneurons in situ. J Neurophysiol 100:868-878. CrossRef Medline

Zheng W, Feng G, Ren D, Eberl DF, Hannan F, Dubald M, Hall LM (1995) Cloning and characterization of a calcium channel alpha 1 subunit from Drosophila melanogaster with similarity to the rat brain type D isoform. J Neurosci 15:1132-1143. Medline 